\title{
Pathways into the Pacific Equatorial Undercurrent: A Trajectory Analysis*
}

\author{
PAUl J. GOODMAN \\ Lamont-Doherty Earth Observatory, Columbia University, Palisades, New York \\ Wilco Hazeleger and Pedro de Vries \\ Royal Netherlands Meteorological Institute, De Bilt, Netherlands \\ MARK CANE \\ Lamont-Doherty Earth Observatory, Columbia University, Palisades, New York
}

(Manuscript received 17 April 2004, in final form 6 June 2005)

\begin{abstract}
A time-dependent trajectory algorithm is used to determine the sources of the Pacific Ocean Equatorial Undercurrent (EUC) in a global climate model with $14^{\circ}$ (eddy permitting) resolution and forced with realistic winds. The primary sources and pathways are identified, and the transformation of properties in temperature/salinity space is explored. An estimate for the quantity of recirculation, a notoriously difficult property to estimate from observational data, is given. Over two-thirds of the water in the Pacific EUC at $140^{\circ} \mathrm{W}$ originates south of the equator; $70 \%$ of the EUC is ventilated outside of the Tropics (poleward of $13^{\circ} \mathrm{S}$ or $10^{\circ} \mathrm{N}$ ): three-quarters of these extratropical trajectories travel through the western boundary currents between their subduction and incorporation into the EUC, and one-fifth of the extratropical trajectories enter and leave the tropical band at least once before entering the EUC.
\end{abstract}

\section{Introduction}

The Equatorial Undercurrent (EUC) in the Pacific Ocean lies at the base of the equatorial thermocline and is the source of the water that upwells into the thermocline. The EUC was rediscovered by Cromwell et al. (1954) and has been mapped over the years by several studies, most notably the Tahiti-Hawaii Shuttle Experiment (Wyrtki and Kilonsky 1984) and as part of the World Ocean Circulation Experiment (WOCE). The relative contributions from the various sources of the EUC determine the temperature, salinity, and nutrient properties of the equatorial thermocline and will affect biological productivity, carbon exchange with the atmosphere, and the ENSO cycle. Studies based on chlorofluorocarbon, tritium, silicate, and nutrient data

\footnotetext{
* Lamont-Doherty Earth Observatory Contribution Number 6803.
}

Corresponding author address: Paul J. Goodman, IMCS/ Rutgers University, 71 Dudley Rd., New Brunswick, NJ 08901. E-mail: paulg@imcs.rutgers.edu
(Tsuchiya 1981; Tsuchiya et al. 1989; Fine et al. 1994, 2001) have shown that the water in the EUC comes primarily from the South Pacific but, because of the complicated current structure in the western equatorial Pacific, the locations where the temperature and salinity properties of the EUC are set remain elusive. Fine et al. (1994) discuss the importance of the western equatorial Pacific as a water mass crossroads and attribute many of the properties there to the low-latitude western boundary currents that flow equatorward along the eastern coasts of Australia, New Zealand, and the Philippines. Johnson and McPhaden (1999), on the other hand, find that there is a significant contribution from direct interior pathways within the subtropical pycnocline.

The Equatorial Undercurrent has also been linked to longer-term (decadal) climate variability. Gu and Philander (1997) propose that extratropical sea surface temperature anomalies are communicated to the Tropics via intergyre exchange, reappearing along the equator several years after being incorporated into the EUC and brought back to the surface. Zhang et al. (1998) cite a subsurface ocean "bridge" to explain the relationship 
between the warm sea surface temperature (SST) anomaly in the North Pacific during the early 1970s and the subsequent warm SST anomaly along the equator in the 1980s. Schneider et al. (1999) and Hazeleger et al. (2001b), however, have shown that the equatorial warming was more likely caused by changes in the lowlatitude wind stress.

We are going to test two competing theories about the sources of EUC water: either tropical recirculation between the undercurrent and the surrounding water sets the EUC's properties or the EUC's properties are determined through intergyre exchanges that communicate extratropical forcing to the equatorial region. We chose to do this analysis on the results from the Ocean Circulation and Climate Advanced Modeling Project (OCCAM). This simulation is global in scope, has an eddy-permitting resolution, and uses realistic winds for an improved simulation of intergyre transfer. Previous studies have used trajectory analysis to look at various aspects of the Pacific EUC. Lu et al. (1998) used a $3 \frac{1}{2}$ layer model of the Pacific to study the tropical cells and to give a quantitative estimate of the sources of the EUC water. Blanke and Raynaud (1997) use a slightly coarser resolution OGCM simulation of the world from $65^{\circ} \mathrm{S}$ to $47^{\circ} \mathrm{N}$, forced with the Hellerman and Rosenstein wind climatology to quantify the local exchanges as the EUC flows from Indonesia to Peru. Huang and Liu (1999) examined the tropicalsubtropical exchange using the Florida State University (FSU) wind climatology, but in a Pacific-only model with no Indonesian Throughflow.

We use the mean seasonal averages of the more detailed OCCAM output to derive our mean ocean state and choose to ignore variability. The seasonal mean is adequate to resolve processes that take many years to develop, and sensitivity experiments that we conduct using 5-day averages are not significantly different.

This study is a hydrographic analysis of the sources of the EUC and the transformation of its constituent water masses. The output from a model simulation is explored by backtracking trajectories along streamlines until they reach the mixed layer. Rodgers et al. (2003) carried out a similar study exploring extratropical sources of the EUC in the Ocean Parellelise (OPA) model, although they employed a different trajectory algorithm as well as different starting and ending criteria. Differences between that study and the other earlier studies and this one will be noted as they arise. Temperature and salinity properties are mapped onto the trajectories to give an indication of where these properties are changed. We perform quantitative calculations of the transports from various locations and from various initial water masses as they are transformed into the relatively uniform core of the EUC.

We first discuss the data, algorithms, and procedures used in this study. We then discuss the effects of seasonality, residual mean versus Eulerian mean velocity fields, particle size, and seeding frequency related to the statistics provided by the trajectory algorithm. We next describe the sources of the EUC based on both their location and their water mass characteristics. This is followed by a hydrographic analysis of the transformations experienced along the various trajectories and a brief discussion of the implications.

\section{Data and procedures}

\section{a. The OCCAM model}

This study uses model output obtained from calculations with the Ocean Circulation and Climate Advanced Modeling Project (Webb et al. 1997; Saunders et al. 1999) simulation as the source of data to which the trajectory algorithm is applied. The OCCAM simulation is discussed fully in Webb et al. (1998), and only the relevant details will be discussed here. The data are on a $0.25^{\circ} \times 0.25^{\circ}$ grid with 36 levels spanning $5500 \mathrm{~m}$, increasing from $20 \mathrm{~m}$ at the surface to $255 \mathrm{~m}$ at the bottom, covering the entire globe. The model's surface temperature and salinity were restored to the surface temperature and salinity fields from the World Ocean Atlas (WOA94 hereinafter) (Levitus and Boyer 1994; Levitus et al. 1994) with a time scale of 30 days. The monthly averaged wind stresses from European Centre for Medium-Range Weather Forecasts (ECMWF; calculated from years 1986-88; Gibson et al. 1997) are applied for the first 8 years of the simulation. In the following 3 years, the 6-hourly winds and wind stresses for 1993-95 are applied. A Laplacian scheme for horizontal diffusion and viscosity is used with coefficients of 100 and $200 \mathrm{~m}^{2} \mathrm{~s}^{-1}$, respectively. The vertical mixing of tracers is according to the Richardson-numberdependent scheme by Pacanowski and Philander (1981) that results in vertical diffusivities of $0.5 \mathrm{~cm}^{2} \mathrm{~s}^{-1}$ away from regions with strong shear.

The OCCAM simulation spanned 11 years; data from years 9-11 inclusive were averaged seasonally and annually to create the various datasets. It must be noted that 11 years is not a very long simulation, and there is still drift in the deeper water column. Lee et al. (2002) have shown that drift is significant only for deeper water masses, which are not considered in this paper. We are focused on the surface and upper thermocline, however, which respond primarily to the wind forcing and should be well established after this time. The OCCAM run was initialized from WOA94, so the mixing pro- 
cesses that are driven by subduction are, to first order, included in the simulation. Moreover, overturning streamfunctions in density coordinates show that below the mixed layer and at depths above about $500 \mathrm{~m}$ $\left(\sim \sigma_{\theta}=26.8\right)$ the diapycnal transports are small in the model (see Fig. 1d of Hazeleger et al. 2001a and Fig. 5d of Hazeleger et al. 2003). We, therefore, feel confident that our results are robust.

Transports obtained from mean velocities will be referred to as the Eulerian mean transports. These do not completely describe the advection of water masses, as the latter generally follow isopycnal surfaces that may move as a function of time. The eddy/variabilityinduced or "residual" transports arise as a result of the correlation between layer thickness and velocity variations (McDougall 1998; McIntosh and McDougall 1996; Drijfhout et al. 2003). These residual transports, which are calculated from the 5-day running mean data, need to be taken into account or else spurious diapycnal forces may be introduced into the calculations. The simulated velocities and layer thicknesses were correlated and time averaged over years and seasons. We add these residual transports to the Eulerian mean transports to obtain fields, which will be referred to as residual mean transports (Hazeleger et al. 2001a, 2003). Note that interannual variabilities also give rise to residual transports.

\section{b. The trajectory algorithm}

The time-dependent trajectory algorithm employed in this study was developed by de Vries and Döös (2001) and is a descendant of the steady-state trajectory algorithm developed by Döös (1995) and Blanke and Raynaud (1997). The trajectory algorithm allows for time-varying velocity data to be incorporated into the trajectory analysis. The effect of neglecting this time interpolation has been studied in Drijfhout et al. (2003). Because season-to-season data variations are much larger than month-to-month ones, sudden switches of season introduce large, spurious diapycnal transports. Errors of up to $20 \%$ were found if no interpolation was used. To retain a correct mean seasonal cycle all seasonally varying fields were interpolated according to the method of Killworth (1996). Each particle is volume conserving and follows true streamlines through the simulated velocity field. The method used here follows mass, not tracers. Therefore: 1) it is essential that it is volume conserving, 2) a trajectory is assigned a specific transport, and 3) its value should be small enough to resolve divergences and convergences of streamlines; in other words, in regions of high velocity shear, numerics may create inconsistent statistics of trajectories through these regions when the particle size is too large. The other quantities, like temperature and salinity, are followed along-trajectory; that is, these are given by the model, which does include diffusion. The streamlines themselves also implicitly contain the effects of momentum diffusion.

Since the trajectory model only requires the velocity fields, which are known for each season, it can trace the particles forward or backward in time. Note that we are following transports and streamlines, not tracers: trajectory ages will not necessarily equal tracer ages. Trajectories represent tracers only in a "center of mass" fashion, and the "trajectory age" is precisely the advective age. In this study we will only refer to the median age when giving statistics of transit times for the trajectories. The use of a mean age weights those trajectories that take the longest path.

The particles are seeded uniformly in space over the face of each grid box that meets the starting criteria (Blanke and Raynaud 1997). The number of particles is proportional to the transport across the face of the grid box. In this way they are grouped in regions where the transport is highest. Each particle's trajectory is then individually calculated from one grid box to the next until it reaches the ending criteria. The trajectory algorithm keeps track of the time elapsed and the position and direction of the particle. It has also been configured to interpolate the temperature, salinity and density of the local environment (as simulated by OCCAM) onto the position of the particle at several intermediary sections between its starting and ending locations. At each intermediary crossing (of a predetermined latitude or longitude), we recorded the location, temperature, salinity, density, and age of the last crossing before entering the EUC, as well as the volume of total crossings for each trajectory in order to get some idea of the recirculations present in the model. Since the particles themselves do not change their volume, the total number of crossings at a given section can be determined by the adding the volume of the particle to the total each time it crosses.

In the seasonal runs, we performed several experiments in which the seeding frequency was varied. In the first case the particles are seeded at the middle of each season; in the next case, we seeded the same number of particles at four different times during each season (16 seedings over the course of the year); and in the last case we seeded eight times per season (32 total seedings). The diagnosed trajectories, transports, and water mass transformations were quite robust to the seeding frequency in that each run differed by no more than a few percent for any measurement. 


\section{c. Methods}

We chose the core of the Pacific's EUC at $140^{\circ} \mathrm{W}$ as our starting point and traced the particles backward in time until they intersected the local mixed layer, crossed $55^{\circ} \mathrm{S}$, or crossed $120^{\circ} \mathrm{E}$ south of Australia. We also allowed for the possibility of trajectories beginning in the Bering Sea, north of $65^{\circ} \mathrm{N}$, or beginning in the Indian Ocean and flowing eastward in the Indonesian Throughflow, but neither of these paths was realized in any experiment. The choice of $140^{\circ} \mathrm{W}$ was somewhat arbitrary; our only criterion was to choose a longitude downstream of the Hawaii-to-Tahiti Shuttle Experiment data (Wyrtki and Kilonsky 1984). For the annual runs, we used the annual mean EUC as our starting point, and the mixed layer depths were determined from the annual-mean data. For the seasonal runs, we use each season's EUC and the deepest mixed-layer depth that occurs during the 3-month season. The core of the EUC is defined as those points between $3^{\circ} \mathrm{S}$ and $3^{\circ} \mathrm{N}$ where the zonal velocity is greater than $15 \mathrm{~cm} \mathrm{~s}^{-1}$ eastward (Fig. 1) and deeper than the mixed layer. These definitions for the EUC are fairly typical of other studies (Blanke and Raynaud 1997; Rodgers et al. 2003) although ours is generally more restrictive by not including westward flowing particles and those moving too slowly.

The transport through each grid box (the speed times the cross-sectional area) that meets this criterion is divided into roughly 2500 parcels, seeded at regular intervals across the face of the grid box. The EUC in OCCAM transports about $25 \mathrm{~Sv}\left(\mathrm{~Sv} \equiv 10^{6} \mathrm{~m}^{3} \mathrm{~s}^{-1}\right)$ so there are approximately 10000 trajectories calculated in the annual study and in the study in which we seeded once per season, while we follow $\sim 40000$ trajectories in the four-seedings-per-season run, and $\sim 80000$ in the case with eight seedings per season. The different number of calculated trajectories leads to different average sizes for each parcel: $\sim 2500 \mathrm{~m}^{3} \mathrm{~s}^{-1}$ (or $2.5 \mathrm{mSv}$ : 1 milliSverdrup $=10^{3} \mathrm{~m}^{3} \mathrm{~s}^{-1}$ ) with 10000 trajectories, $\sim 620$ $\mathrm{m}^{3} \mathrm{~s}^{-1}$ with 40000 trajectories and $\sim 310 \mathrm{~m}^{3} \mathrm{~s}^{-1}$ with 80000 trajectories.

The mixed layer depths (MLDs) (Fig. 2) used in this study are the maximum MLD for each three-month season. Each month's MLD was defined as the depth over which the density is within $0.1 \mathrm{~kg} \mathrm{~m}^{-3}$ of the surface value. In comparison, Blanke and Raynaud (1997) define their EUC as those points at $150^{\circ} \mathrm{W}$ with an eastward velocity between $3.55^{\circ} \mathrm{S}$ and $3.55^{\circ} \mathrm{N}$ above 495 m. Rodgers et al. (2003) chose their starting criteria as all points along $151^{\circ} \mathrm{W}$ between $3^{\circ} \mathrm{S}$ and $3^{\circ} \mathrm{N}$ with an eastward velocity below the mixed layer and above 612 $\mathrm{m}$. Their mixed layer depth was defined as the point at

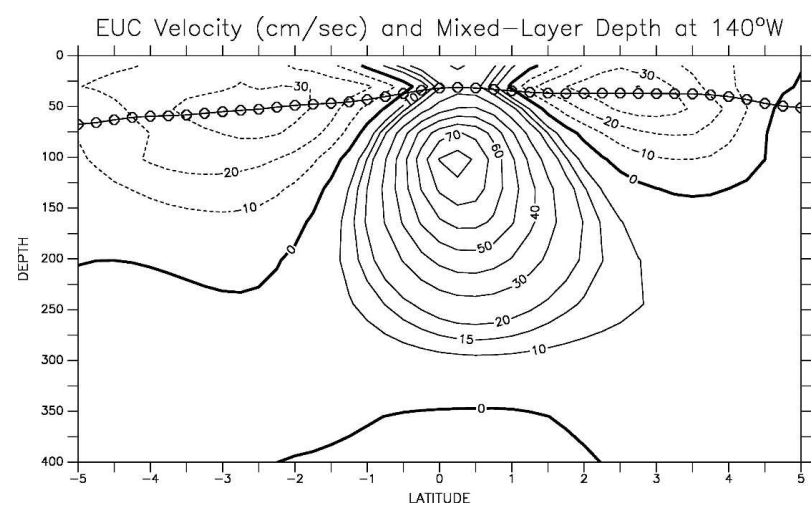

FIG. 1. Equatorial Undercurrent speed $\left(\mathrm{cm} \mathrm{s}^{-1}\right)$ at $140^{\circ} \mathrm{W}$ during the spring in OCCAM. The black line with circles is the average springtime mixed layer depth.

which the density differed from the surface by $0.01 \mathrm{~kg}$ $\mathrm{m}^{-3}$, a definition that they note may not be well suited to the equatorial region as it leads to too shallow mixed layers in the Tropics and a notable lack of ventilation sources between $10^{\circ} \mathrm{S}$ and $10^{\circ} \mathrm{N}$. Also, their cutoff at $612 \mathrm{~m}$ leads to the inclusion of parcels with a much greater density in EUC.

We emphasize that the trajectories in the model follow streamlines through the fluid, calculated solely from the velocity fields that are not necessarily coincident with isopycnals. The particles themselves have no inherent density; their location and age are calculated by the trajectory algorithm and the OCCAM density, and temperature and salinity are mapped onto the particle. These are recorded at the starting and ending sections as well as several other intermediate sections.

We note that the relative statistics described here do not depend on the size of the particles: when we seeded the EUC with particles sizes smaller than $2500 \mathrm{~m}^{3} \mathrm{~s}^{-1}$, the ratio of southern to northern source waters and the fraction of particles intersecting the mixed layer differed by no more than a few percent. Although we tracked the particles backward in time, the following discussion will describe the simulation forward in time with the particles subducting out of the mixed layer at the beginning and their subsequent arrival at the EUC at the end.

\section{Sensitivity of the trajectory algorithm}

We conducted several experiments with different velocity fields. These included annual mean velocities without the residual transport (Eulerian mean) and with the residual transport (residual mean), seasonal mean velocities (Eulerian mean and residual mean), and 5-day mean velocities. We also explored the effects 


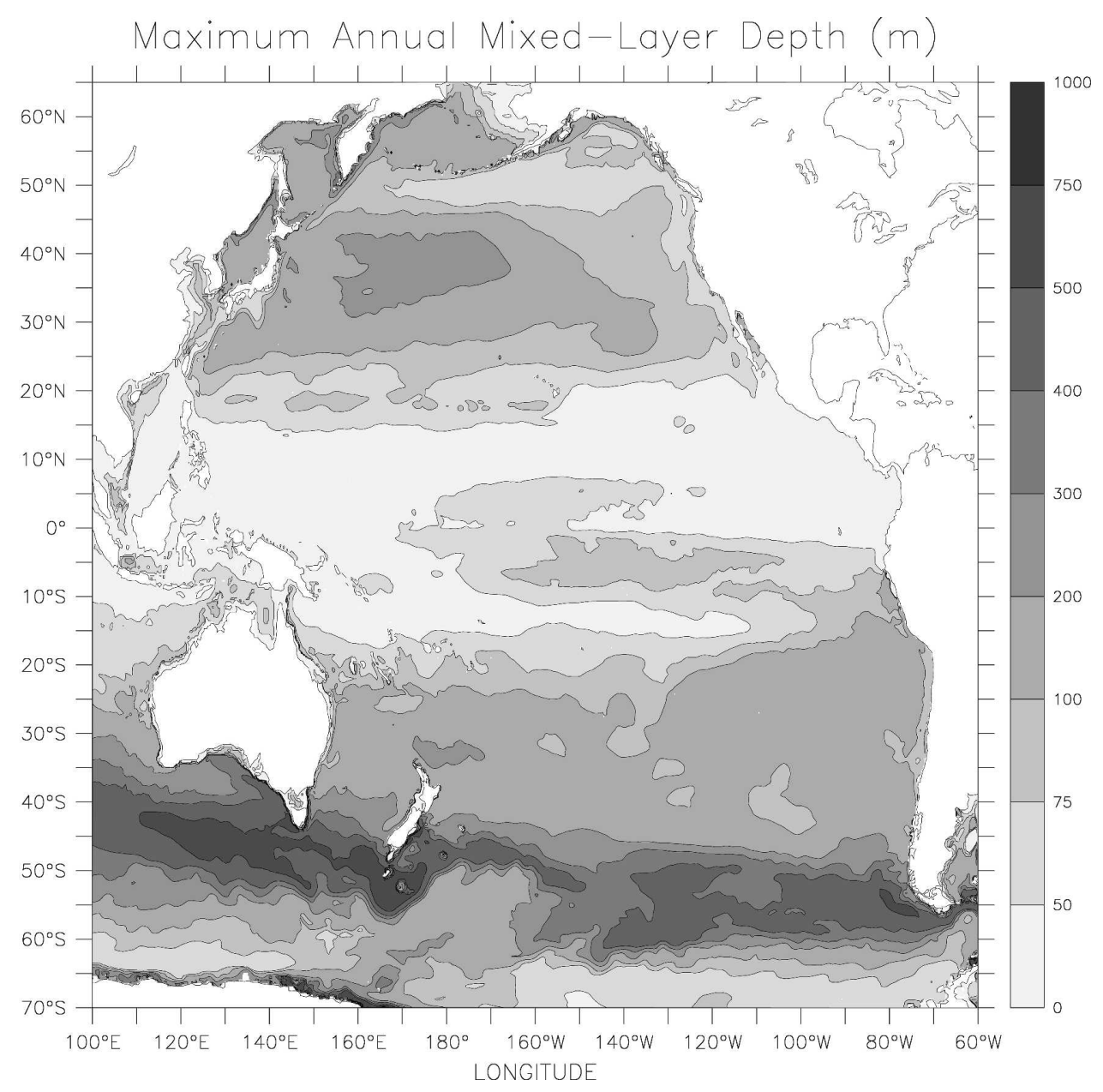

FIG. 2. Maximum annual mixed layer depth (m) in OCCAM.

of increasing the number of seedings per season to explore the sensitivity of the algorithm to both time of year and particle size.

\section{a. Eulerian mean versus residual mean}

We first conducted experiments using two different velocity fields: the seasonal Eulerian mean velocities and the seasonal residual mean velocities. The strength of the modeled EUC has a transport of 21-29 Sv in both cases. These agree well with the published estimates based on both current meters (32 Sv: Lukas and Firing 1984; 23 and 30 Sv: Wyrtki and Kilonsky 1984), and geostrophy (26 Sv: Lukas and Firing 1984), especially considering that we have only included the core of the EUC. The locations where the backtracked trajectories intersect the mixed layer were binned into $1^{\circ} \times 1^{\circ}$ boxes and their volumes were summed for each of the datasets. The experiments show that particles ending up in the EUC leave the mixed layer in three main places (Fig. 3): in zonal bands immediately to the north and south of the equator with the southern band having a greater volume; broadly across the South Pacific with the larger part concentrated toward the eastern end of the subtropical gyre and the smaller part in the center of the gyre northeast of New Zealand; and in the North Pacific toward the eastern end of the subtropical gyre.

The main effect of including the residual transports (Fig. 3b) is that the zonal bands near the equator are less intense, closer to the equator, and shifted to the east in the residual mean runs relative to the Eulerian mean runs. Hazeleger et al. (2001a), using the same OCCAM data, reported that the tropical cells in the Pacific disappear when the residual velocities are included in the calculation of the meridional overturning, consistent with the reduction of the number of trajectories leaving the equatorial bands. The elimination of the spurious diapycnal forces related to the tropical cells are a strong motivation for our inclusion of the residual velocities. Hazeleger et al. (2003) reported that the Atlantic EUC, from the same OCCAM data, also 

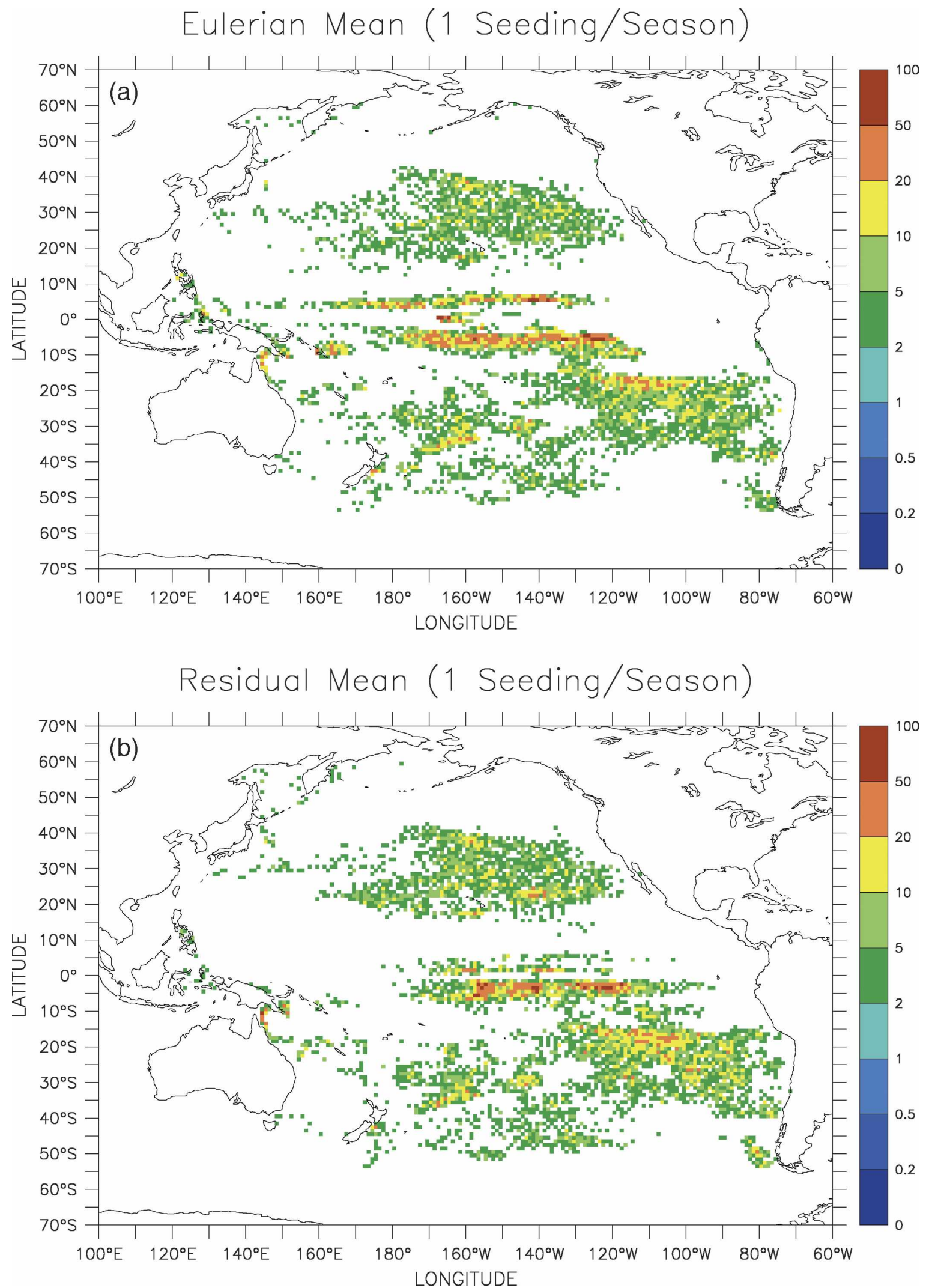

FIG. 3. Volume (mSv) and initial location of water parcels ending in the EUC during the (a) Eulerian-mean and (b) residual-mean seasonal experiments with one seeding per season giving an average particle size of $2500 \mathrm{~m}^{3} \mathrm{~s}^{-1}$. 
showed the same eastward shift in the subduction sites when the residual velocities are used. Differences between that study and this one are largely due to the topographic differences between the Pacific and Atlantic basins. Also, the basinwide meridional overturning circulation in the Atlantic causes a strong north-south asymmetry that is not present in the Pacific. Readers should refer to these studies for a more complete discussion of the differences between Eulerian mean and residual mean transports.

The spatial patterns and quantitative results presented here are consistent with previous studies. The $3^{1 / 2}$ layer model used by Lu et al. (1998) indicated about $2 / 3$ of the EUC water originated south of the equator, the same ratio found here. Huang and Liu (1999) in the National Centers for Environmental Prediction (NCEP) Ocean Model had a greater percentage of northern water in the EUC, but their model has no Indonesian Throughflow, which preferentially draws water from the north relative to the south.

\section{b. Effects of annual, seasonal, or 5-day averages}

We next conducted several experiments in which we used three different sets of velocity fields: the annual average, the seasonal average, and the 5-day means of the velocity fields but with only one year of data. The trajectory algorithm requires that the entire velocity field for the year be held in active memory; using the 5 -day means requires an eighteenfold increase in the amount of computer memory necessary, so these runs were carried out in a reduced domain covering only the North Pacific (north of $5^{\circ} \mathrm{S}$ ). Each of these experiments uses the Eulerian mean velocity fields for the same model year. The use of only one year of data limits the proper construction of a residual mean transport but, as seen in Fig. 3, the use of an Eulerian mean instead of a residual mean does not affect the large-scale dispersion. Figure 4 shows the subduction sites for these three runs. For each of these runs, we used the northern half of the EUC and disallowed for trajectories crossing the equator.

The differences between the annual experiment (Fig. 4a) and the other two are striking. The ventilation sites are much more diffuse in the seasonal and 5-day runs. These changes are due to the dispersion that comes from varying transport velocities instead of the uniform annual-mean transports. The inclusion of a varying mixed layer depth may also play a small role in that particles are more likely to leave the mixed layer when the mixed layer shoals around them. In the annual mean experiment, the trajectories are carried away at a few well-delineated locations: along the eastern and northern edges of the subtropical gyre and in a band at $5^{\circ} \mathrm{N}$. The dispersion of the trajectories between the seasonal (Fig. 4b) and 5-day (Fig. 4c) experiments has not changed significantly in comparison with the annual- to seasonal-mean differences. Differences between these two experiments include an increase and a spreading of the $5^{\circ} \mathrm{N}$ band in the 5-day run and a shift to the eastern end of the subtropical gyre in the seasonal run. Only 3.3 Sv are ventilated north of the equator in the annual experiment, whereas the same $6.1 \mathrm{~Sv}$ are ventilated north of the equator in the other two runs. We must note, however, that there are interannual fluctuations that may lead to differences in the ventilation results. The similarity of Figs. $4 \mathrm{~b}$ and $4 \mathrm{c}$ and the similar statistics of sources and transports (they differ by no more than $10 \%-15 \%$ ), leads us to conclude that the use of seasonally averaged data does not significantly bias our results.

\section{c. Effects of seeding frequency}

The last sensitivity test that we performed was on the frequency of particle seedings per season. The results from one seeding in the middle of each season were shown in Fig. 3. The roughly $25 \mathrm{~Sv}$ EUC was divided into four 2500-trajectory seedings giving a particle size of $2500 \mathrm{~m}^{3} \mathrm{~s}^{-1}$. We also divided the seeding of each season into four (Fig. 5a) and eight (Fig. 5b) parts. As noted above, four (eight) seeds per season is 16 (32) seeds per year, giving an average particle size of 625 (310) $\mathrm{m}^{3} \mathrm{~s}^{-1}$. Increasing the number of trajectories leads to a greater dispersion in their sources; that is, the infrequent sites shown in purple in Fig. $5 \mathrm{~b}$ are absent in Figs. 3 and 5a, but the three figures are not qualitatively different. We want to reiterate that Drijfhout et al. (2003) note that errors of up to $20 \%$ were found in simulations that use seasonal datasets and did not use some form of temporal interpolation. The rest of this study will focus on the results from the eight seedings per season, residual mean experiment.

\section{A geographic analysis}

The residual-mean seasonal dataset has an annual mean EUC of $23.9 \mathrm{~Sv}$ at $140^{\circ} \mathrm{W}$, varying from a low of $21 \mathrm{~Sv}$ in the winter to a high of $29 \mathrm{~Sv}$ in the spring (Fig. 1). Over $97 \%$ of the 76869 trajectories ( $23.3 \mathrm{~Sv}$ ) backtrack from the EUC into the mixed layer, and 2.5\% (0.6 $\mathrm{Sv}$ ) cross $55^{\circ} \mathrm{S}$. (The remaining 13 trajectories begin at $120^{\circ} \mathrm{E}$ between Australia and $55^{\circ} \mathrm{S}$.) Figure 5b shows that the ventilated portion (originating in the mixed layer) subducts primarily from the Southern Hemisphere (south of $13^{\circ} \mathrm{S}, 10.5 \mathrm{~Sv}$ ) and the equatorial region (between $13^{\circ} \mathrm{S}$ and $10^{\circ} \mathrm{N}, 7.2 \mathrm{~Sv}$ ) with a smaller 
Annual Average Velocities

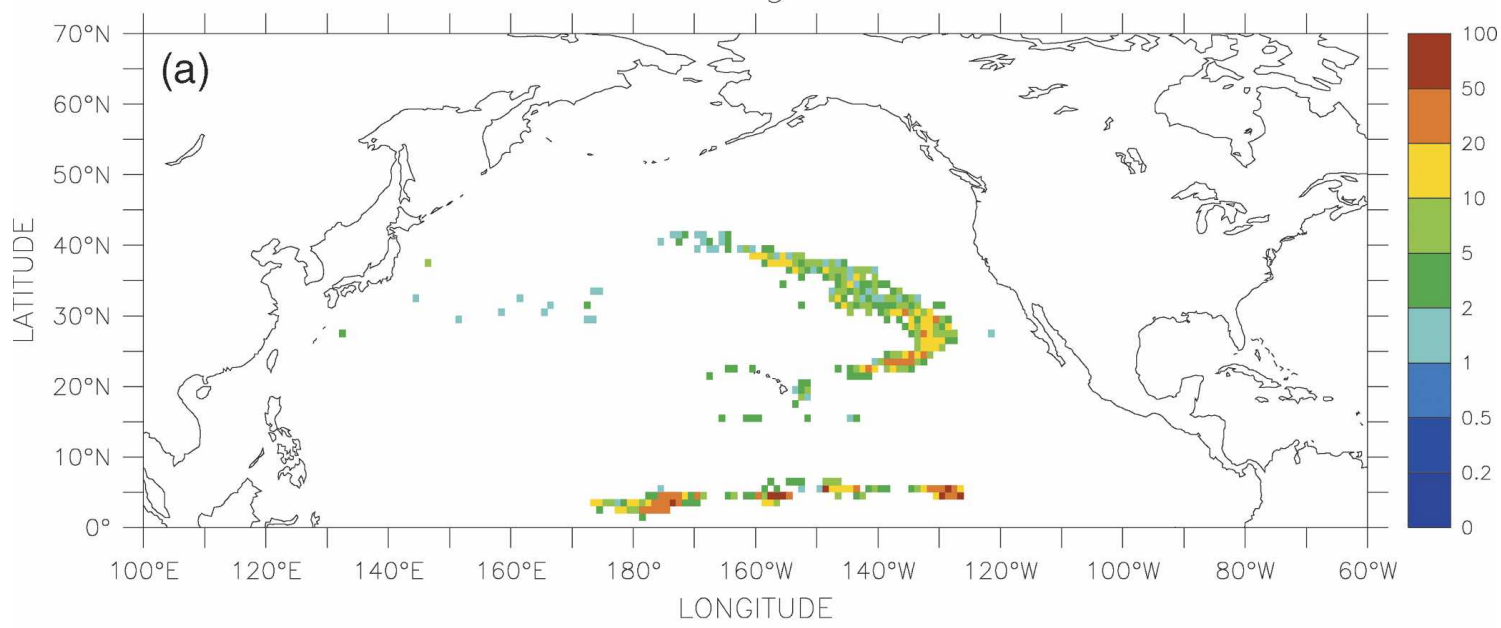

Seasonal Average Velocities

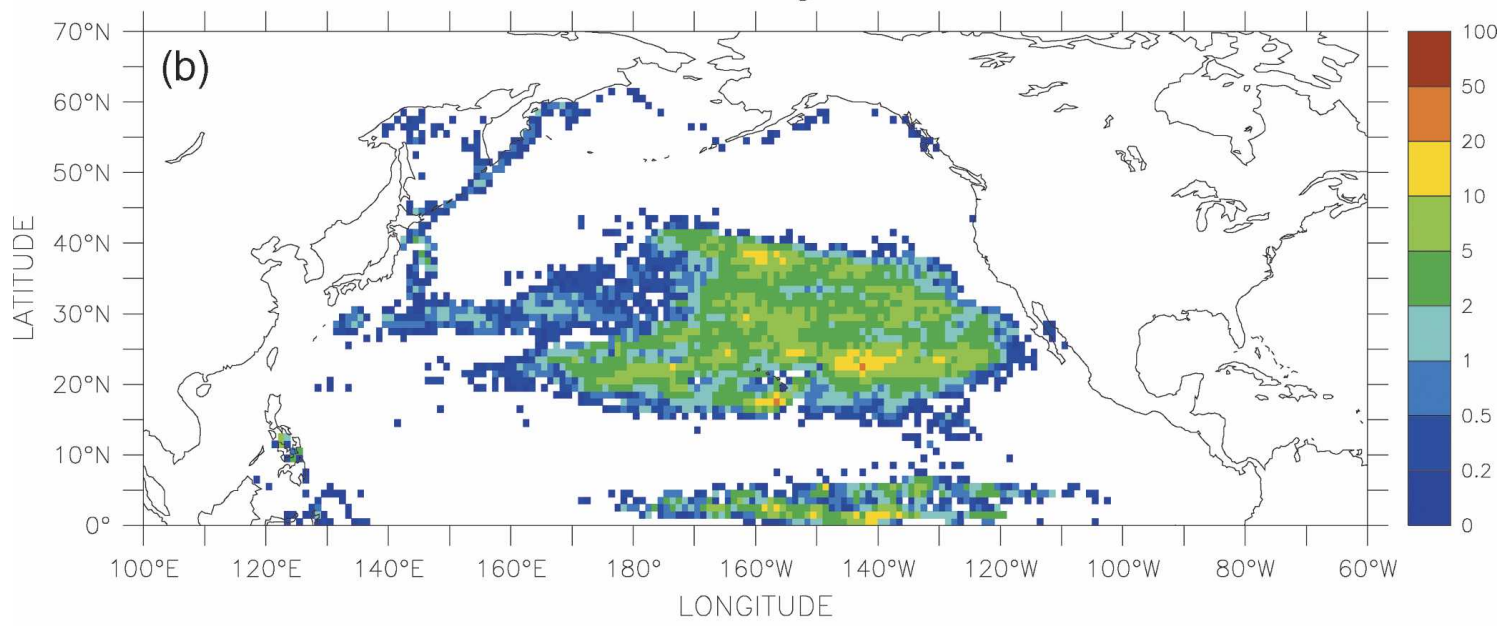

5-Day Average Velocities

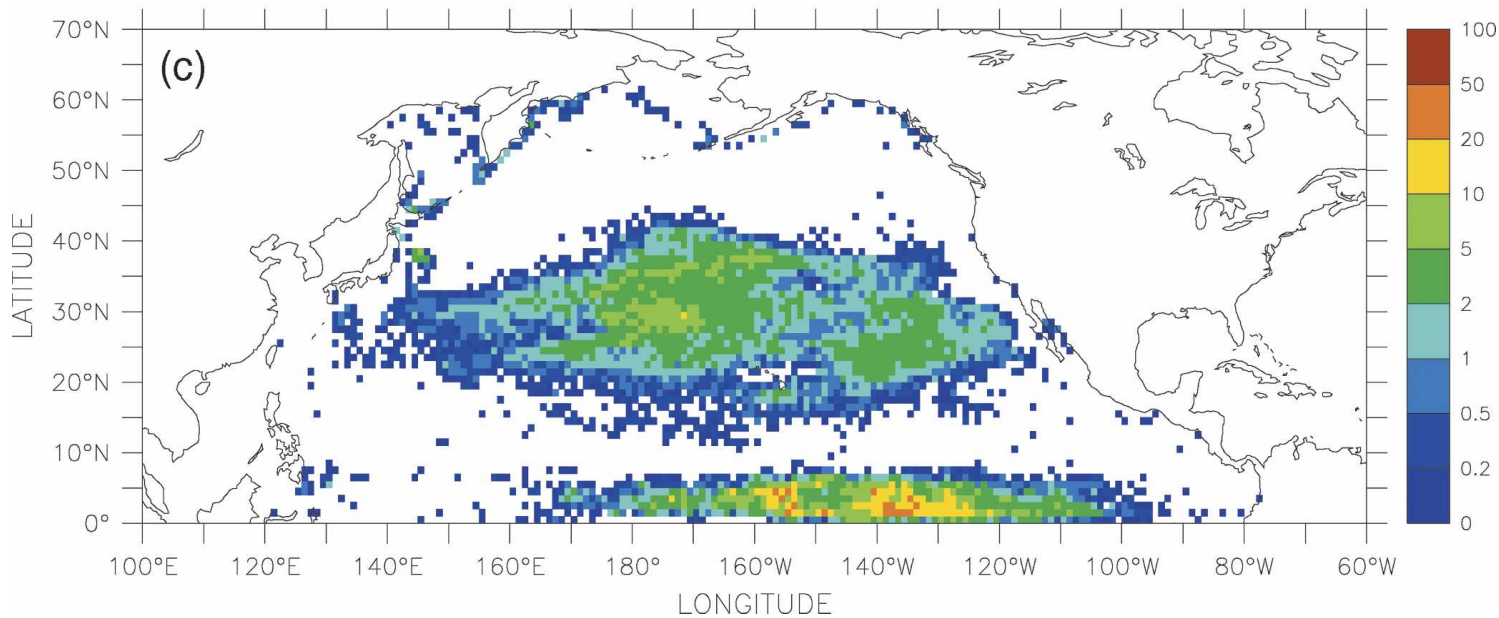

FIG. 4. Volume (mSv) and initial location of water parcels from the North Pacific ending in the EUC during (a) the annual experiment, (b) the seasonal experiment, and (c) the 5-day experiment. For each of these runs, we used the northern half of the EUC only and disallowed for trajectories crossing the equator. 
4 Seedings Per Season

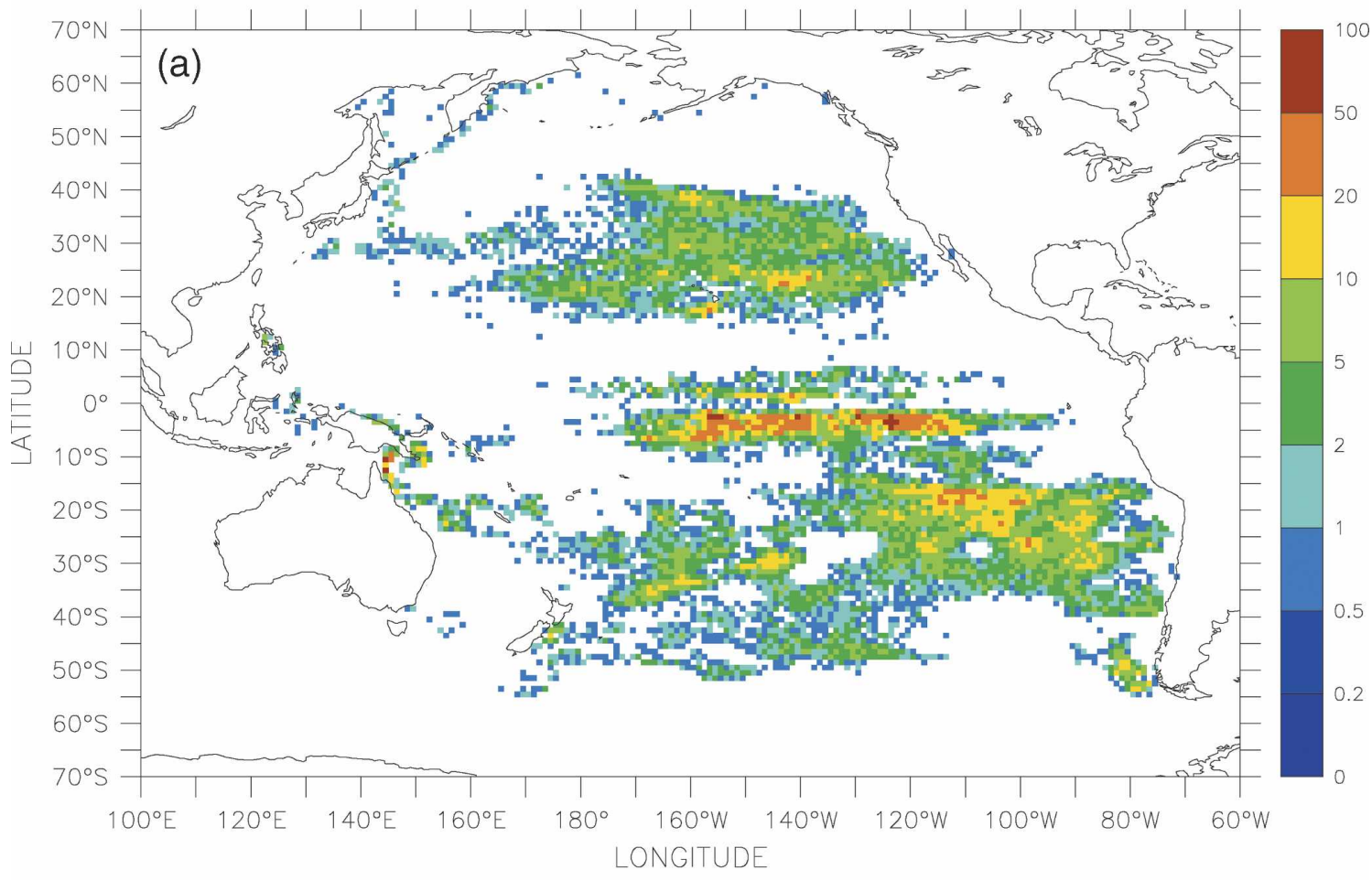

8 Seedings Per Season

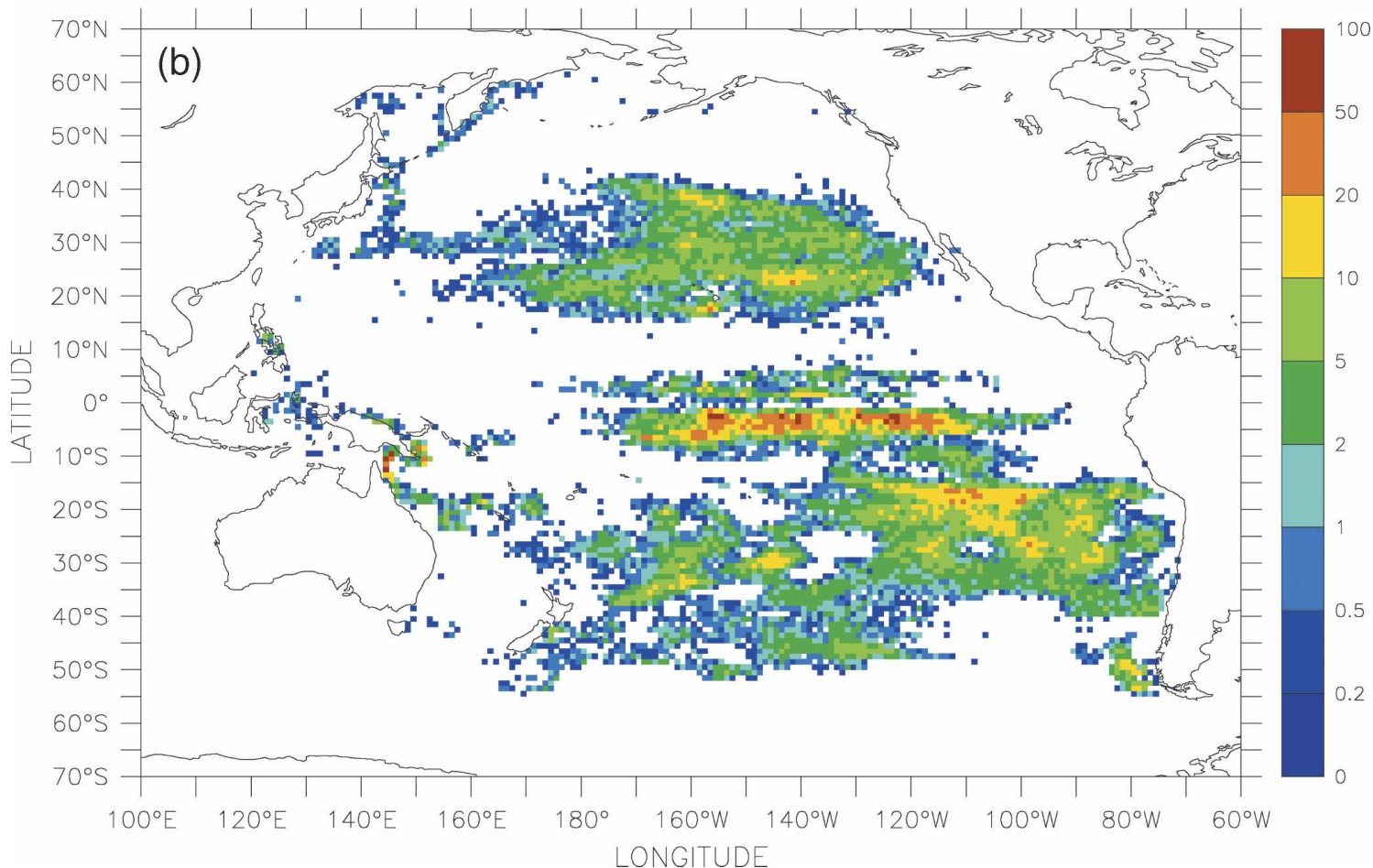

FIG. 5. Volume (mSv) and initial location of water parcels ending in the EUC during the residual-mean seasonal experiment with (a) four separate seedings per season giving an average particle size of $620 \mathrm{~m}^{3} \mathrm{~s}^{-1}$ and (b) eight separate seedings per season giving an average particle size of $310 \mathrm{~m}^{3} \mathrm{~s}^{-1}$. 


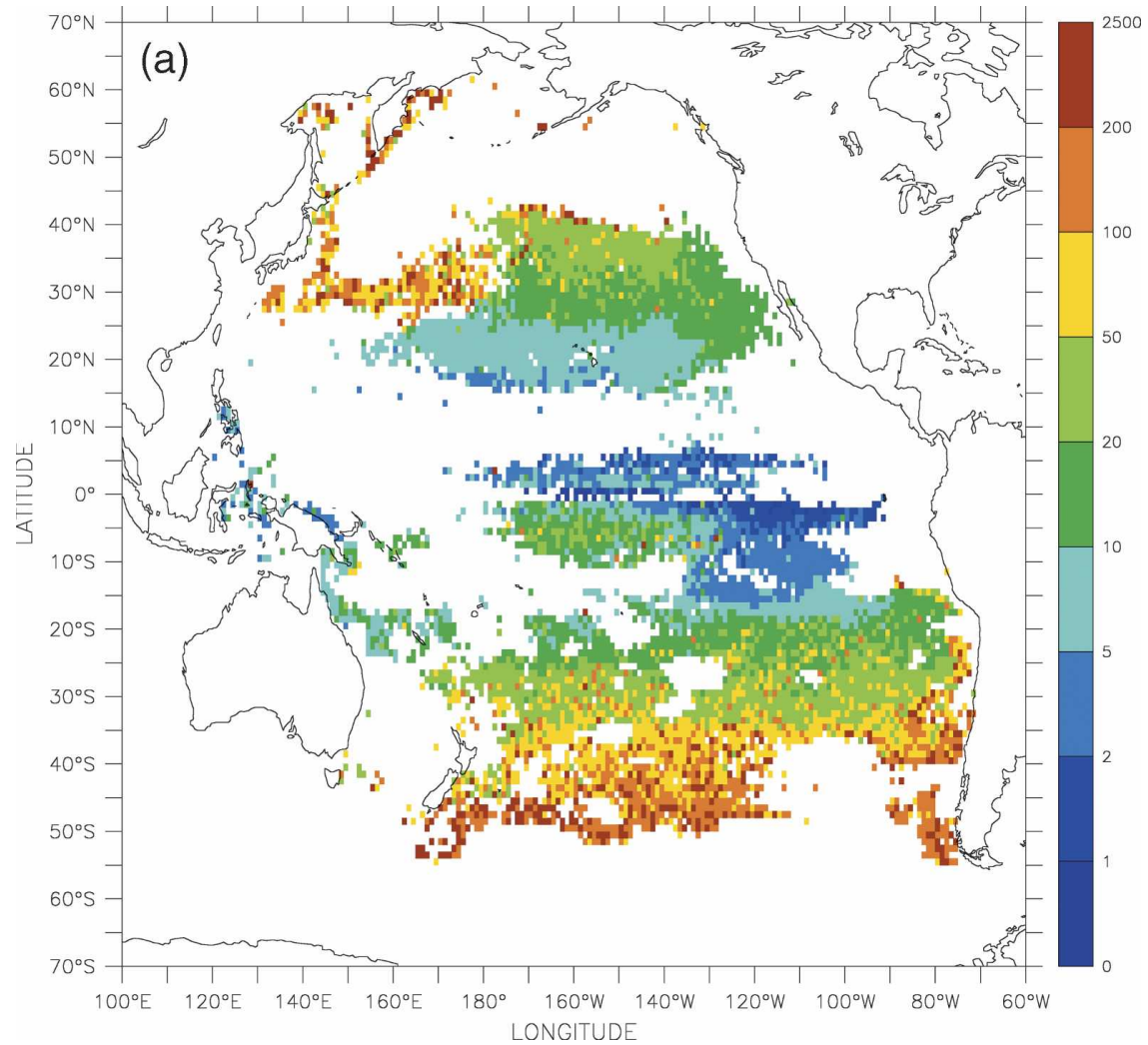

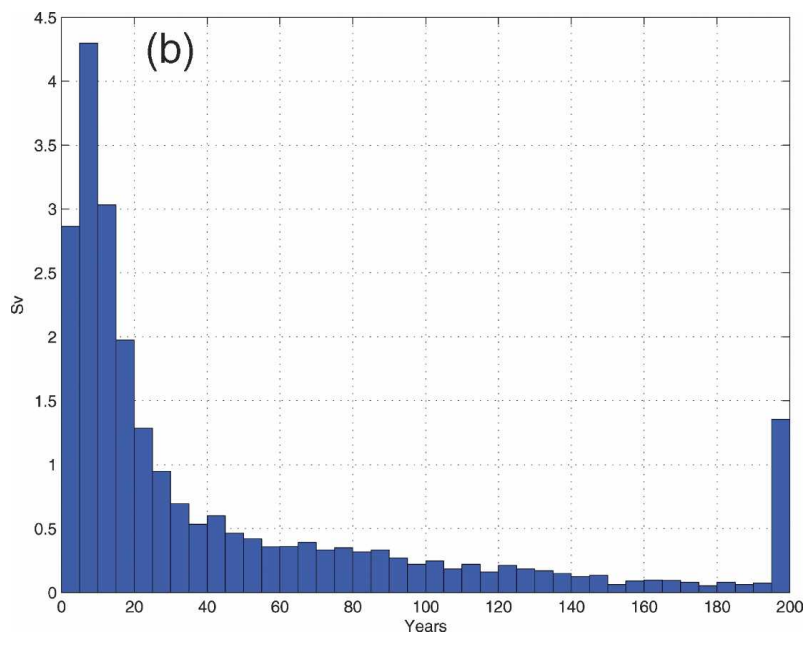

portion from the Northern Hemisphere (north of $10^{\circ} \mathrm{N}$, 5.5 Sv). Totals of $6.5 \mathrm{~Sv}$ and $0.7 \mathrm{~Sv}$ are ventilated in bands between $13^{\circ} \mathrm{S}$ and $0^{\circ}$ and between $0^{\circ}$ and $10^{\circ} \mathrm{N}$, respectively. These are the South Equatorial Current (SEC) and North Equatorial Current (NEC), which are "the major upper ocean flows supplying the western boundary" (Fine et al. 1994) and are therefore a conduit into the EUC. Of the 7.2 Sv ventilated in the equatorial region, $4.2 \mathrm{~Sv}$ or $58 \%$ never crosses beyond $10^{\circ} \mathrm{N}$ or $13^{\circ} \mathrm{S}$ before entering the EUC. The median time for equatorial trajectories between subduction and the
FIG. 6. Time between subduction and the EUC in years: (a) plan view and (b) binned into 5-yr windows. The last bin is the total volume that ventilates after year 195 .

EUC is $3.8 \mathrm{yr}$ for those that never leave the Tropics, $15.1 \mathrm{yr}$ for those that do leave, and $4.7 \mathrm{yr}$ for all equatorial trajectories (Fig. 6).

Summaries of the positions occupied by the trajectories are shown in Fig. 7. These summaries or "footprints" are calculated by integrating with depth and time the number of trajectories that pass through a given grid cell. The footprints reveal where the particles have passed, regardless of depth or direction. For trajectories originating north of the equator (Fig. 7a), the major avenues are in the North Equatorial Current (the 

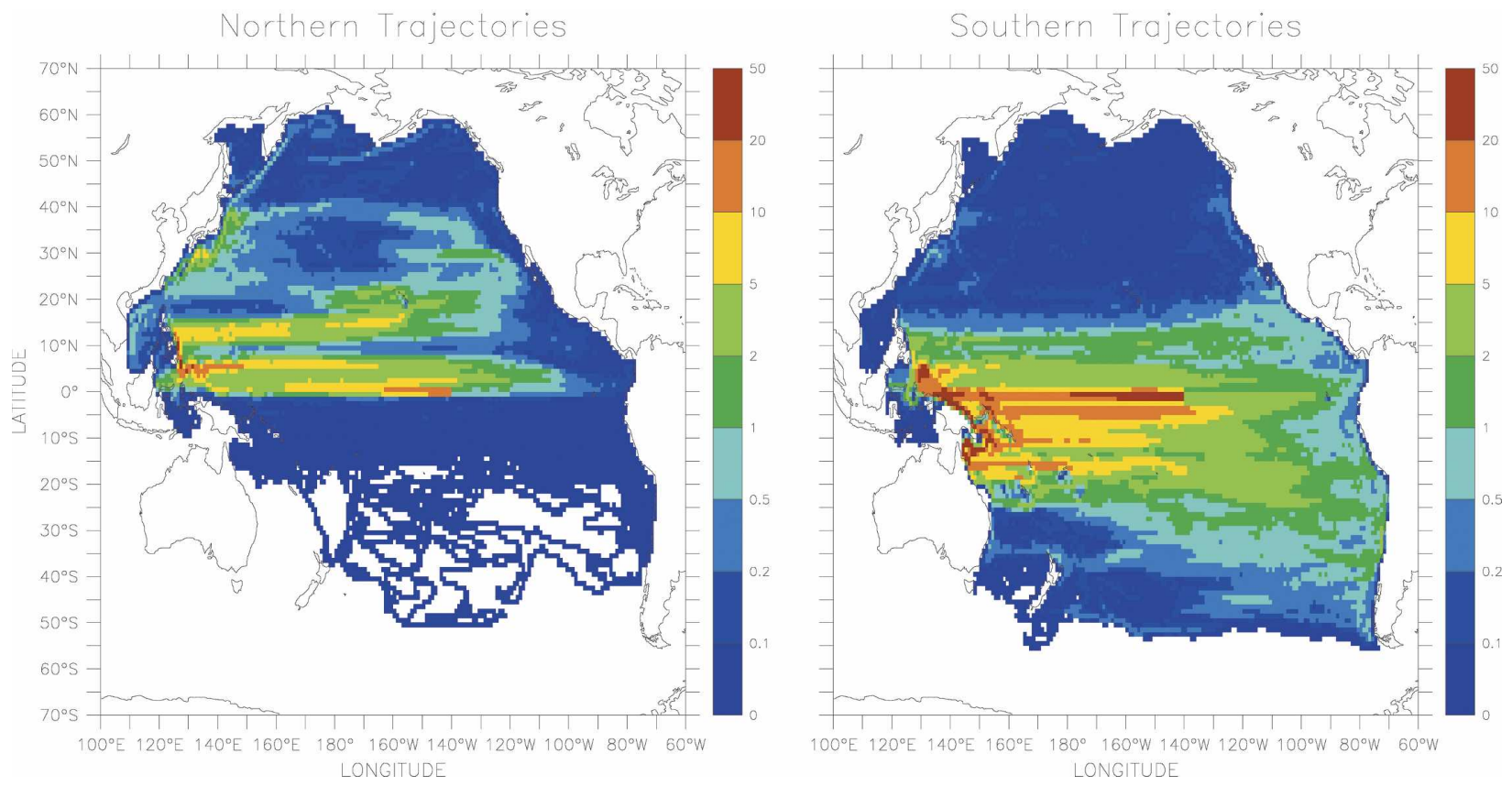

FIG. 7. Positions occupied by the trajectories between subduction and the EUC (at any depth) for (a) particles subducting north of the equator and (b) particles subducting south of the equator. Units are volume: $10^{6} \mathrm{~m}^{3}$.

zonal band at $\left.13^{\circ} \mathrm{N}\right)$, the Mindanao Current, the North Equatorial Countercurrent (NECC) (the zonal band at $5^{\circ} \mathrm{N}$ east of the Philippines), and the Equatorial Undercurrent. Moderate activity is also seen in the Kuroshio region and along the eastern edge of the gyre. When comparing northern trajectories with southern trajectories (Fig. 7b), the differences in cross-equatorial flow are striking. The fundamental differences between the North and South Pacific Oceans are due to the geometries of the coastlines and to the presence of the Indonesian Throughflow (ITF). Water in the Mindanao Current will either flow through the ITF or turn eastward at $5^{\circ} \mathrm{N}$ to join the NECC. Only 1732 particles (out of 17659 ) that leave the mixed layer north of the $10^{\circ} \mathrm{N}$ cross $5^{\circ} \mathrm{S}$ and their total transport is $0.04 \mathrm{~Sv}$.

The Southern Hemisphere trajectories go everywhere: 4.4 Sv of South Pacific water cross $5^{\circ} \mathrm{N}$ and these particles recirculate an average of four to five times across this latitude before settling into the EUC. Many features of the equatorial current structure described by Fine et al. (1994) are highlighted by the southern particles, including the New Guinea Coastal Current and the New Guinea Coastal Undercurrent (east of New Guinea), the several branches of the South Equatorial Current (zonal bands at $17^{\circ}$ and $4^{\circ} \mathrm{S}$ ), the South Equatorial Countercurrent (at $10^{\circ} \mathrm{S}$ ), and the Mindanao and Halmahera eddies (at $5^{\circ} \mathrm{N}, 130^{\circ} \mathrm{E}$ and $1^{\circ} \mathrm{N}$, $140^{\circ} \mathrm{E}$, respectively). The bands of weaker activity at $10^{\circ} \mathrm{N}$ and $13^{\circ} \mathrm{S}$ motivated our choice of these latitudes to define our equatorial region.

In the South Pacific, $10.5 \mathrm{~Sv}$ are ventilated south of $13^{\circ} \mathrm{S}$. These trajectories begin primarily in the eastern half of the subtropical gyre (Fig. 3). By definition, all of these trajectories end up in the EUC, so the longitude at which they cross $13^{\circ} \mathrm{S}$ headed northward for the last time is indicative of the path they take. Figure 8a shows the transports of these trajectories at $13^{\circ} \mathrm{S}$ binned by longitude (black) and the integrated transport (gray, beginning in the west). The particles that cross in the western boundary current as part of the SEC or the Great Barrier Reef Undercurrent between the northern tip of Australia and $160^{\circ} \mathrm{E}$; these account for $6.9 \mathrm{~Sv}$ or $66 \%$ of the total. The separation between those trajectories taking an interior route (those that cross east of $160^{\circ} \mathrm{W}$, totaling $3.6 \mathrm{~Sv}$ ) and those in the western boundary is clear. The particles traveling through the western boundary have a median age of $14 \mathrm{yr}$ at the last crossing and a median age of $50 \mathrm{yr}$ when they enter the EUC (Fig. 6a). The interior particles have a median age of $10 \mathrm{yr}$ at $13^{\circ} \mathrm{S}$ and $20 \mathrm{yr}$ at the EUC (Fig. 6a). Note again that trajectory ages and tracer ages are not identical. The large median age difference implies that particles following the western boundary route are more involved in recirculations and/or the the zonal excursions seen in the footprints.

In the North Pacific, 5.5 Sv leave the mixed layer 

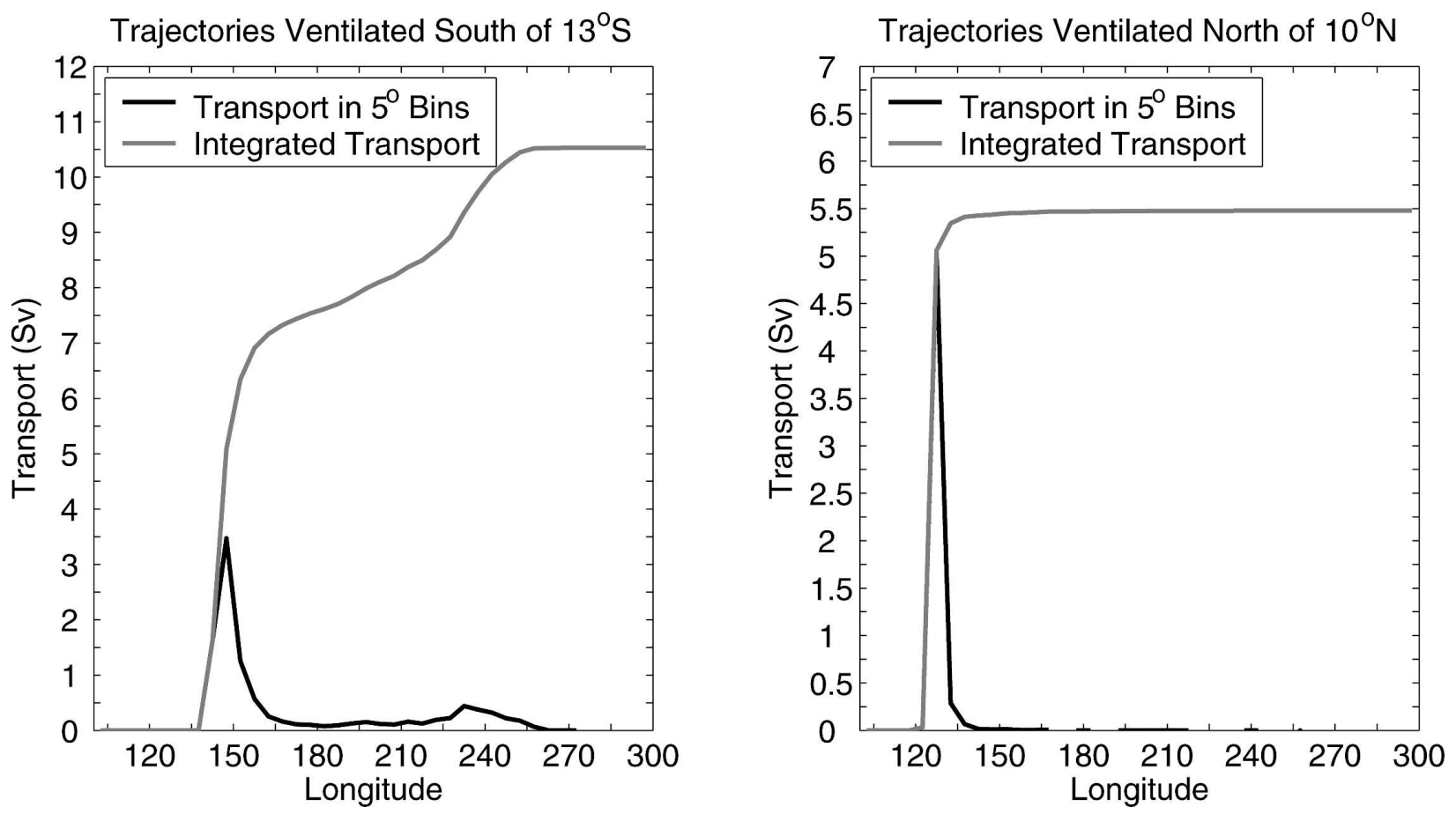

FIG. 8. Transport across (a) $13^{\circ} \mathrm{S}$ and (b) $10^{\circ} \mathrm{N}$ binned by longitude. The black lines are the actual transport in each $5^{\circ}$ longitude bin, and the gray lines are the integrated transport (west to east).

north of $10^{\circ} \mathrm{N}$. Figure $8 \mathrm{~b}$ shows the longitude at which these trajectories cross $10^{\circ} \mathrm{N}$ southward for the last time. The western boundary is even more dominant than in the Southern Hemisphere with $5.1 \mathrm{~Sv}$ or $92 \%$ of the trajectories crossing between the Philippines and $130^{\circ} \mathrm{E}$ in the Mindanao Current. These particles have taken a median transit time of $4.5 \mathrm{yr}$ to reach $10^{\circ} \mathrm{N}$ and then take an additional $9.3 \mathrm{yr}$ to reach the EUC (Fig. 6a).

Blanke and Raynaud (1997, their Fig. 9) show a much different census of the originating trajectories from both north and south of the equator. That study concludes that less than $25 \%$ of the water originating south of $15^{\circ} \mathrm{S}$ crosses that latitude in the boundary current and over $50 \%$ of the water crosses between $130^{\circ}$ and $100^{\circ} \mathrm{W}$. In the north, they have no EUC water moving southward in the Mindanao Current, and $80 \%$ of the northern-source EUC water crosses $15^{\circ} \mathrm{N}$ between $160^{\circ} \mathrm{E}$ and $120^{\circ} \mathrm{W}$.

Recirculation, a difficult quantity and quality to measure in the real ocean, can be explored quite effectively with the trajectory algorithm. The large transports seen in Fig. 7 give a preliminary indication that many of the trajectories cross by the same point more than once on their journey from subduction to the EUC, and this is bolstered by the long times experienced by the particles as seen in Fig. 6. By summing the total transports at various intermediary sections, we can put a quantitative value on the total amounts of recirculation present in the velocity field. Figure 9 is a cartoon of the possible paths by which a particle subducting south of the equator can travel to reach the EUC. If the particle subducts north of $13^{\circ} \mathrm{S}$, the "direct" route has no southward or northward crossing of $13^{\circ} \mathrm{S}$, and the "indirect" route must cross at least once in both directions. There are 6.5 $\mathrm{Sv}$ of EUC water ventilated between the equator and $13^{\circ} \mathrm{S} ; 4.0 \mathrm{~Sv}$ of this takes the direct route, consistent with the idea that the South Equatorial Current is fed into the western Pacific "crossroads" and then returns eastward in the EUC. We can tell how many trajectories have ever crossed $160^{\circ} \mathrm{E}$ : that is, have been in the western Pacific at some point in their journey. Ninetyfour percent of the particles are subducted east of $160^{\circ} \mathrm{E}$ and $77 \%$ of these cross $160^{\circ} \mathrm{E}$ at least once. Particles taking the direct route have a median travel time of $4.5 \mathrm{yr}$ until entering the EUC, whereas the indirect route particles have a median age of $16 \mathrm{yr}$ in the EUC.

For the trajectories originating south of $13^{\circ} \mathrm{S}$, the median ventilation time is 43 years and the spectrum of ages is shown in Fig. 9b. This is somewhat misleading and our understanding of the circulation is substantially improved when we compare the direct and indirect paths. The direct route has precisely one northward crossing of $13^{\circ} \mathrm{S}$, and the indirect route has at least one 

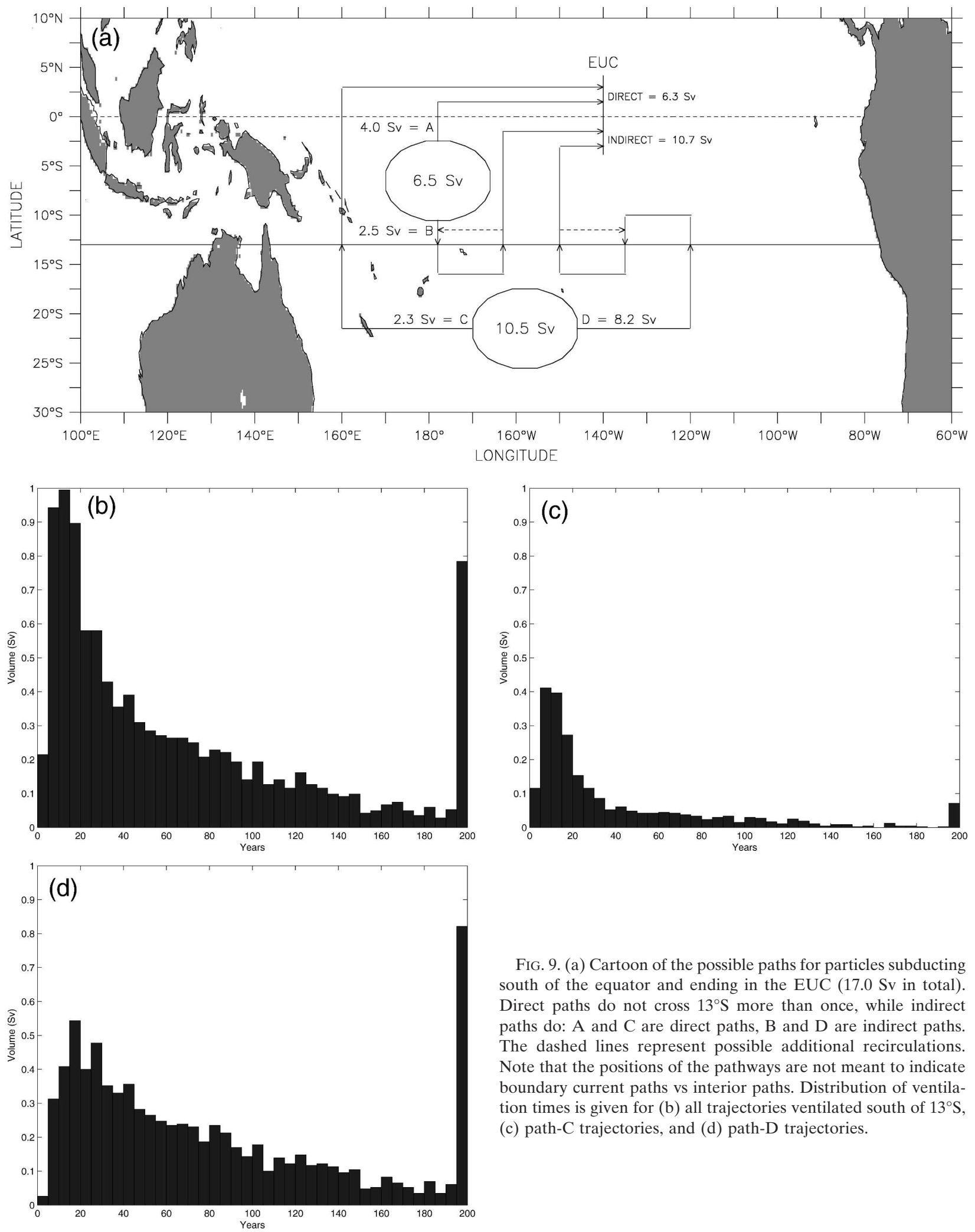

FIG. 9. (a) Cartoon of the possible paths for particles subducting south of the equator and ending in the EUC (17.0 Sv in total). Direct paths do not cross $13^{\circ} \mathrm{S}$ more than once, while indirect paths do: $\mathrm{A}$ and $\mathrm{C}$ are direct paths, $\mathrm{B}$ and $\mathrm{D}$ are indirect paths. The dashed lines represent possible additional recirculations. Note that the positions of the pathways are not meant to indicate boundary current paths vs interior paths. Distribution of ventilation times is given for (b) all trajectories ventilated south of $13^{\circ} \mathrm{S}$, (c) path-C trajectories, and (d) path-D trajectories. 
TABle 1. Water masses that end up in the Pacific EUC in the OCCAM simulation.

\begin{tabular}{|c|c|c|c|c|}
\hline Name & $\begin{array}{c}\text { Density range } \\
\qquad\left(\sigma_{\theta}\right)\end{array}$ & $\begin{array}{l}\text { Volume } \\
\left(10^{6} \mathrm{~m}^{3}\right)\end{array}$ & $\begin{array}{l}\text { Percent of } \\
\text { the EUC }\end{array}$ & $\begin{array}{c}\text { Median age } \\
\quad(\mathrm{yr})\end{array}$ \\
\hline Tropical Water-north (TWn) & $<24.0$ & 2.0 & 8.5 & 5.9 \\
\hline Tropical Water-south (TWs) & $<24.5$ & 7.4 & 31.2 & 8.3 \\
\hline Eastern Subtropical Mode Water-north (ESTMWn) & $24.0<\ldots<25.4$ & 3.1 & 13.2 & 16.2 \\
\hline Eastern Subtropical Mode Water-south (ESTMWs) & $24.5<\ldots<25.8$ & 7.3 & 30.6 & 27.5 \\
\hline Central Subtropical Mode Water-north (CSTMWn) & $25.4<\ldots<26.5$ & 1.0 & 4.3 & 36.2 \\
\hline Central Subtropical Mode Water-south (CSTMWs) & $25.8<\ldots<26.5$ & 1.2 & 4.9 & 79.2 \\
\hline North Pacific Intermediate Water (NPIW) & $>26.5$ & 0.02 & 0.1 & 106.4 \\
\hline Subantarctic Mode Water (SAMW) & $>26.5$ & 1.1 & 4.7 & 129.7 \\
\hline Unventilated & $>27.0$ & 0.6 & 2.6 & 1105.8 \\
\hline
\end{tabular}

southward crossing. Of the total $10.5 \mathrm{~Sv}$ ventilated south of $13^{\circ} \mathrm{S}, 2.3 \mathrm{~Sv}$ cross $13^{\circ} \mathrm{S}$ only once, and the other $8.2 \mathrm{~Sv}$ make at least one recirculation, and average three southward crossings. As expected, the direct particles spend much less time between subduction and the EUC, $19 \mathrm{yr}$ versus $62 \mathrm{yr}$ for particles taking the indirect route. The spectrum of ventilation times shows that the direct path (Fig. 9c) has a steep drop after $20 \mathrm{yr}$ and a small tail of long-lived trajectories. The indirect trajectories (Fig. 9d) show a much more gradual decrease indicating the large amount of recirculation and points to the possibility of many transits into and out of the tropical band before the final entrainment into the EUC.

\section{A density class analysis}

The previous section compared the trajectories based on their initial geographical location. We will now do an alternate analysis based on the initial density of the particles. Table 1 shows the initial density at which the ventilated trajectories leave the mixed layer. The density intervals were taken from the analysis of Fine et al. (2001). Although these water masses are often defined by additional characteristics such as potential vorticity, tracer content, etc., these intervals were chosen so that the model output from OCCAM could be compared directly with observations. We have defined North Pacific Intermediate Water (NPIW) as northern water with density greater than 26.5 and Subantarctic Mode Water (SAMW) as southern water with a density between 26.5 and 27.1. Fine et al. (2001) also define Antarctic Intermediate Water (AAIW) with densities between 27.0 and 27.3, but there is almost none of that class represented north of $55^{\circ} \mathrm{S}$ in our experiment, so we classify any ventilated southern water denser than 26.5 as SAMW.

The densities in the EUC are between 23.8 and 26.3, a reasonably wide spread but, as will be discussed later, the trajectories are well grouped in temperaturesalinity $(T-S)$ space. The EUC in the OPA model described by Rodgers et al. (2003) has densities between 22.3 and 27.2 , a significantly larger spread than seen in OCCAM, which is due to their starting criteria of all eastward flowing water between $3^{\circ} \mathrm{S}$ and $3^{\circ} \mathrm{N}$ and above $612 \mathrm{~m}$. ESTMW is well delineated by the trajectory model, and accounts for about one-half of each hemisphere's contribution to the EUC. CSTMW is also represented (1.2 Sv south and 1.0 Sv north). The denser water masses (SAMW, NPIW) from each hemisphere make a small contribution to the EUC: only $1.1 \mathrm{~Sv}$ of SAMW from the south and $0.02 \mathrm{~Sv}$ of NPIW make it to the EUC. There are, however, an additional $0.6 \mathrm{~Sv}$ that enter the domain across $55^{\circ} \mathrm{S}$ that never intersect the mixed layer before entering the EUC: $0.24 \mathrm{~Sv}$ are in the density range for AAIW (27.0-27.3) and these cross $55^{\circ} \mathrm{S}$ at depths between 500 and $1100 \mathrm{~m}$, while the rest likely represents Circumpolar Water.

Since the denser water masses are formed at higher latitudes, it seems reasonable to look at the total meridional transport of all the trajectories at the most poleward sections of the model. The net equatorward flows of water with a density greater than 26.5 are 0.6 $\mathrm{Sv}$ at $20^{\circ} \mathrm{N}$ and $2.1 \mathrm{~Sv}$ at $30^{\circ} \mathrm{S}$. Rodgers et al. (2003), however, report that as much as 6-7 Sv originally denser than 26.2 ends up in the EUC $(\sim 20 \%$ of their total.)

The change in density from the starts of the trajectories (at subduction) to their ends (at the EUC) is summarized in Table 2. The lightest water masses (TWN and TWS) get denser. The subtropical water masses from the north remain roughly the same, although $20 \%$ of the ESTWN gets reclassified into the denser CSTWN range and $20 \%$ of the CSTWN gets reclassified into the lighter ESTWN range. In the Southern Hemisphere, 90\% eastern subtropical water (ESTWS) stays in the same density class from start to finish, whereas only $20 \%$ of CSTWS remains un- 
TABLE 2. The change in volume (mSv) between subduction and the EUC as a function of water mass. The number in parentheses is the initial volume $(\mathrm{mSv})$ of each water mass at subduction. Note that the unventilated water that enters the domain across $55^{\circ} \mathrm{S}$ is included in the water mass labeled as SAMW. Here NH and SH denote the Northern and Southern Hemispheres, respectively.

\begin{tabular}{|c|c|c|c|c|c|c|c|c|c|c|}
\hline \multirow[b]{2}{*}{$\begin{array}{l}\text { In the } \\
\text { EUC }\end{array}$} & \multicolumn{10}{|c|}{ At subduction } \\
\hline & NH & $\begin{array}{l}\text { TWN } \\
(2027)\end{array}$ & $\begin{array}{c}\text { ESTWN } \\
(3143)\end{array}$ & $\begin{array}{c}\text { CSTWN } \\
(1028)\end{array}$ & $\begin{array}{l}\text { NPIW } \\
(24)\end{array}$ & $\mathrm{SH}$ & $\begin{array}{l}\text { TWS } \\
(7436)\end{array}$ & $\begin{array}{c}\text { ESTWS } \\
\text { (7303) }\end{array}$ & $\begin{array}{c}\text { CSTWS } \\
(1162)\end{array}$ & $\begin{array}{l}\text { SAMW } \\
(1742)\end{array}$ \\
\hline & TWN & -2018 & 0 & 1 & 0 & TWS & -5977 & 105 & 4 & 7 \\
\hline & ESTWN & 2017 & -646 & 206 & 11 & ESTWS & 5968 & -733 & 925 & 1703 \\
\hline & CSTWN & 1 & 646 & -207 & 13 & CSTWS & 9 & 628 & -929 & 32 \\
\hline & NPIW & 0 & 0 & 0 & -24 & SAMW & 0 & 0 & 0 & -1742 \\
\hline
\end{tabular}

changed. The densest water masses initially (NPIW and SAWM) all get lighter by the time they reach the EUC, and $98 \%$ of the water from the ACC ends up in the ESTWS range.

\section{A hydrographic analysis}

Water masses are generally characterized by their temperature and salinity, so we present a hydrographic analysis of the water masses at the start, end, and intermediate points along the trajectories. Figure 10a shows the $T-S$ properties of the ventilated trajectories at the point of subduction and Fig. 10b is an enlarged version of the EUC, color-coded by the location of ventilation. The EUC in OCCAM is a well-defined water mass with a small range in salinity and a larger range in temperature. As expected, the fresher particles in the EUC have mostly originated north of the equator, the saltier ones have come from the south, and the equa- torial particles are a bit warmer on average. Asking how and where the particles are transformed from their widely disparate $T-S$ properties at subduction to the tight grouping in the EUC (box in Fig. 10a) is equivalent to asking how and where the mixing processes occur.

A comparison of the $T-S$ characteristics of the ventilated trajectories $(3.5 \mathrm{~Sv})$ beginning south of $30^{\circ} \mathrm{S}$ is presented in Fig. 11a. In the 23 years after being subducted (yellow circles), these particles become slightly colder and fresher before they cross $30^{\circ} \mathrm{S}$ northward for the last time (blue circles, Figs. 11a,b), but there is still a reasonably wide spread in both temperature and salinity space. The particles are mostly in the northward flowing portion of the subtropical gyre as is seen in Fig. 11b. Crossing $13^{\circ} \mathrm{S}$ for the last time (red circles, Figs. 11a,b: 37 years later), these trajectories have been concentrated in $T-S$ space, and again the range in salinity is reduced far more than the range in temperature.
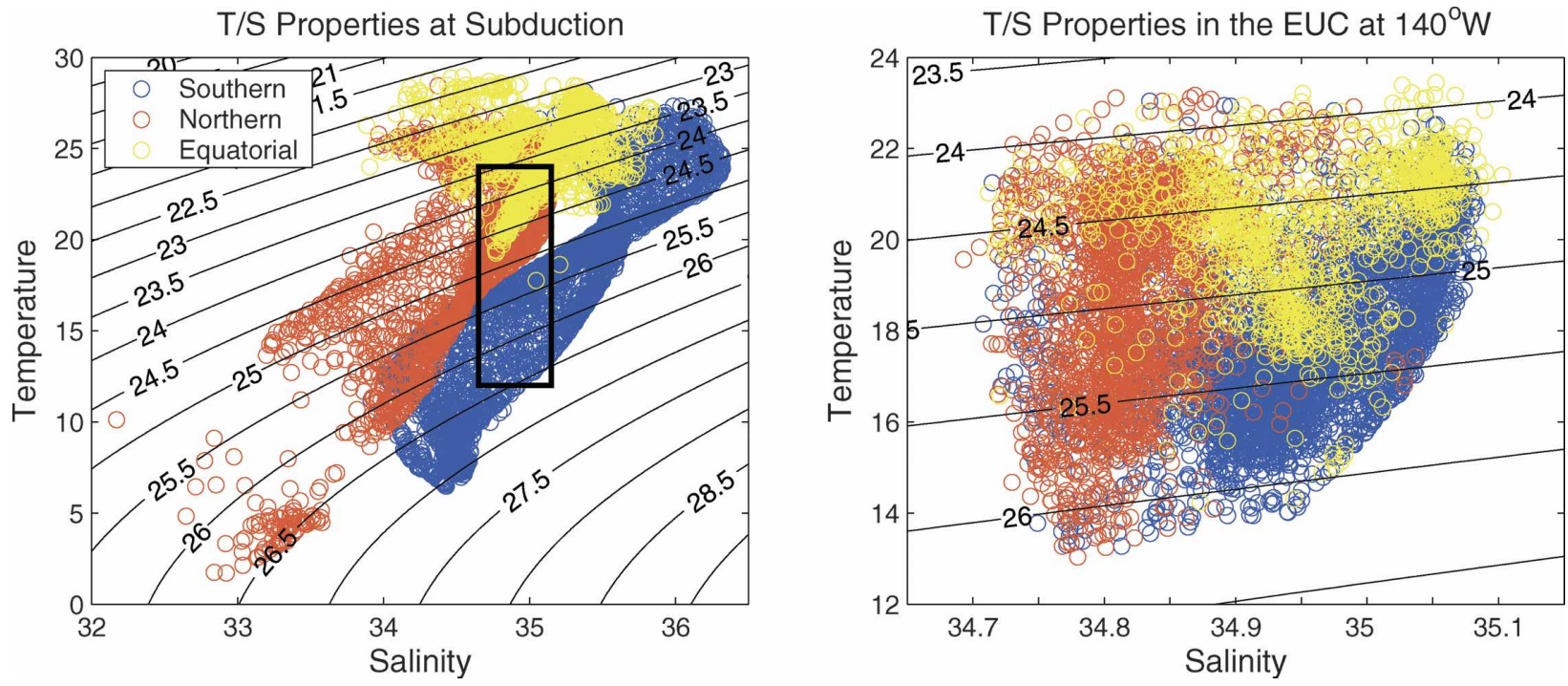

FIG. 10. Temperature vs salinity characteristics for all of the ventilated trajectories (a) at subduction and (b) in the EUC. The black box in (a) matches the outer limits of (b). Blue circles are trajectories originating in the South Pacific, red circles are trajectories originating in the North Pacific, and yellow circles are trajectories originating in the equatorial Pacific. 
T/S Properties

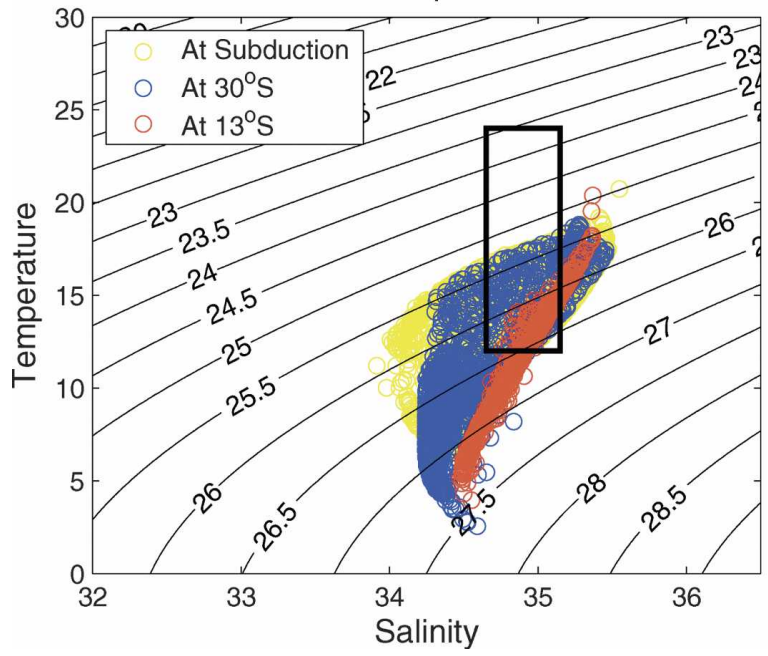

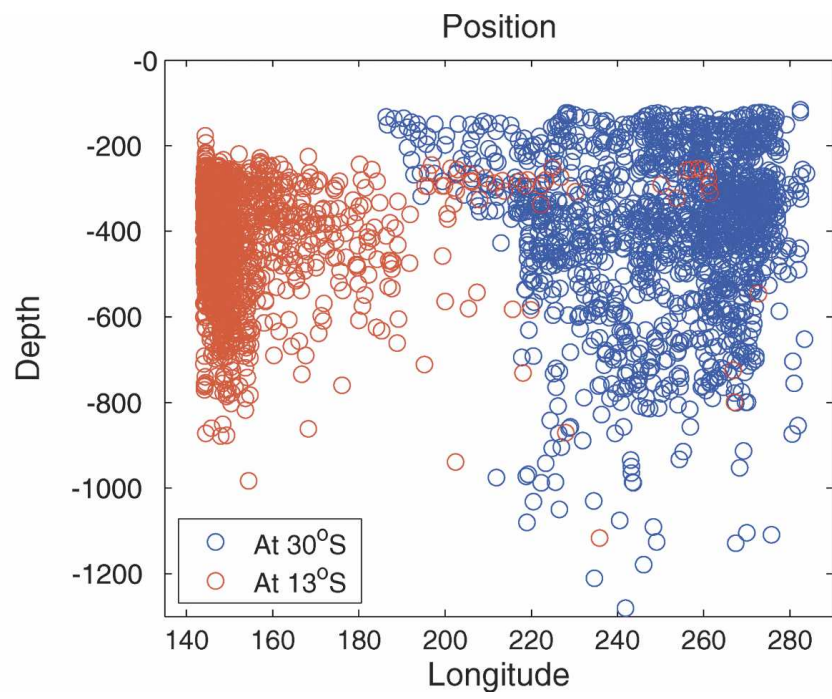

FIG. 11. (a) The temperature vs salinity characteristics of particles ventilated south of $30^{\circ} \mathrm{S}$ at subduction (yellow), crossing $30^{\circ} \mathrm{S}$ (blue), and crossing $13^{\circ} \mathrm{S}$ (red). (b) The longitude vs depth of the same trajectories at $30^{\circ} \mathrm{S}$ (blue) and $13^{\circ} \mathrm{S}$ (red). The black box in (a) matches the outer limits of Fig. 10b.

These trajectories take an additional 30 years to reach the EUC (a median transit time of $90 \mathrm{yr}$ from start to finish) where they are generally warmer and have a more uniform salinity (Fig. 10b).

\section{Discussion}

The sources of the Pacific Equatorial Undercurrent are explored using data from the OCCAM model and a volume-conserving trajectory algorithm. Backtracking the particles in the core of the EUC until they hit the seasonally varying mixed layer reveals several critical facts relating to the sources of the EUC. The results of this study support the hypothesis that the ultimate source of the EUC water is extratropical: 20 of the 24 Sv spend at least part of their lifetimes poleward of $5^{\circ} \mathrm{S}$ or $5^{\circ} \mathrm{N}$. This tends to rebut the local recirculation hypothesis, although local recirculation between $5^{\circ} \mathrm{S}$ and $5^{\circ} \mathrm{N}$ is certainly present in the OCCAM simulation.

The trajectory algorithm can provide much information that is difficult or impossible to obtain from direct ocean measurements. The sensitivity of the algorithm to residual mean versus Eulerian mean transports is shown to be consistent with previous studies. The sensitivity of the algorithm to annual versus seasonal versus 5-day velocity fields and to seeding frequency is shown to be qualitative rather than quantitative if varying velocity fields are used. Using only the annual-mean velocity field leads to a substantial, and likely unrealistic, decrease in the dispersion of particles and trajectories. Quantitative estimates of the rates of recirculation, as well as determination of the main pathways and mixing time scales, are critical to both ocean tracer and climate studies.

Over $97 \%$ of the particles in the EUC started in the mixed layer north of $55^{\circ} \mathrm{S}$. The main subduction sites are south of $13^{\circ} \mathrm{S}$ in the eastern and central South Pacific subtropical gyre, in the South and North Equatorial Currents, and north of $10^{\circ} \mathrm{N}$ in the eastern and central North Pacific subtropical gyre. The contribution from southern sources is more than double that of northern sources. There is quite a bit of recirculation across every meridional section as is indicated by the trajectory ages. The majority of the high-latitude trajectories enter the Tropics for the last time in the equatorward flowing western boundary currents as described by Fine et al. (1994). The $T-S$ characteristics of the particles are well mixed in these boundary currents, but there is some evidence that much of the mixing (in the OCCAM simulation at least) occurs earlier in their path. There is in general more change in the $T-S$ properties between subduction and the last crossing of a meridional section than there is between that last crossing and the final EUC values. This is further proof that extratopical ventilation is more important than tropical recirculation in setting the properties of EUC water.

Johnson and McPhaden (1999, JM99 hereinafter) report a net interior equatorward flow of $14 \mathrm{~Sv}$ at $8^{\circ} \mathrm{S}$ (east of $165^{\circ} \mathrm{E}$ ) and $6 \mathrm{~Sv}$ at $8^{\circ} \mathrm{N}$ (east of $135^{\circ} \mathrm{E}$ ). An analysis of the annually averaged transport in the OCCAM model versus density across these same sections is shown in Fig. 12 (cf. JM99, Fig. 6). The Southern 

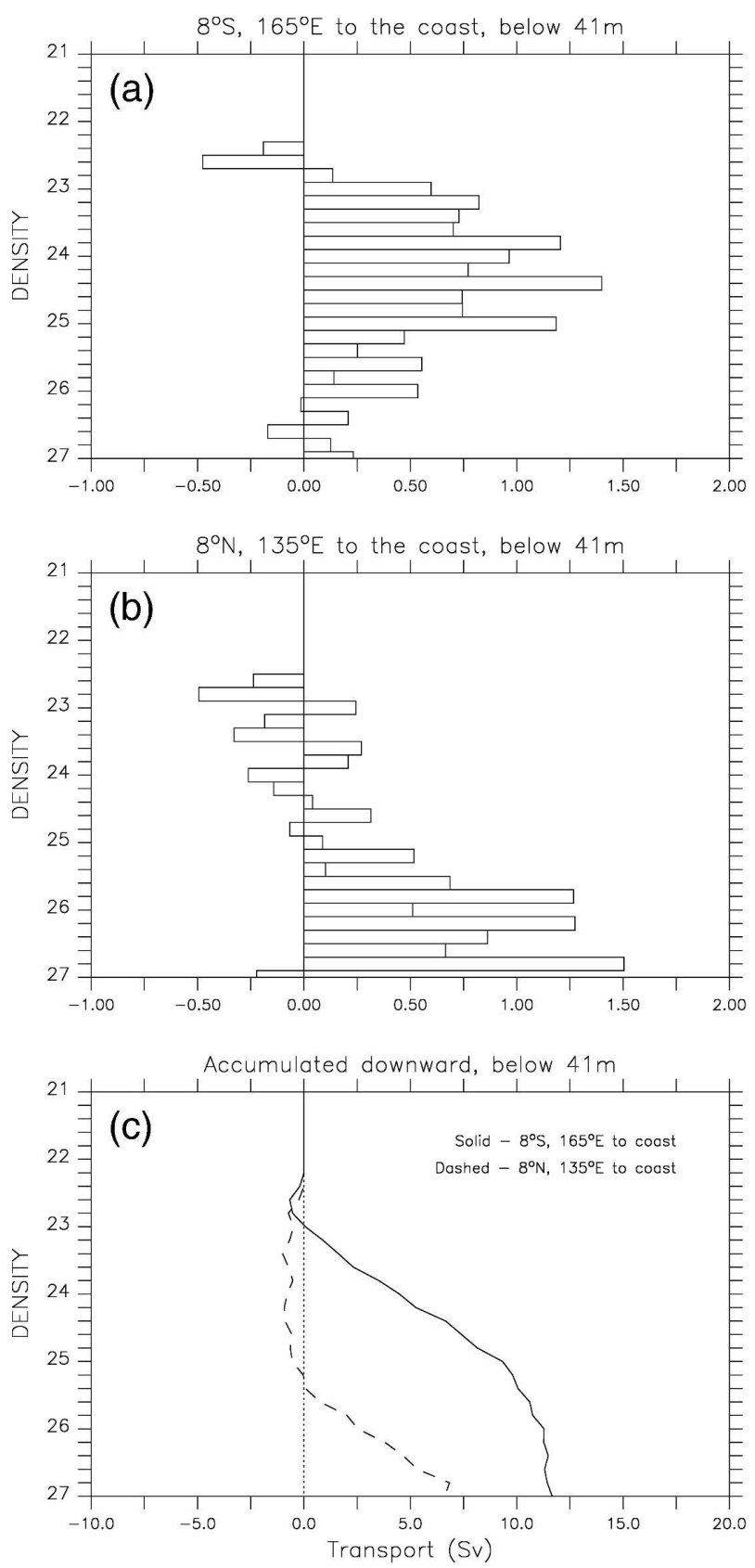

FIG. 12. The net meridional transport binned in density every $0.2 \mathrm{~kg} \mathrm{~m}^{-3}$ from the South American coast to (a) $165^{\circ} \mathrm{E}$ at $8^{\circ} \mathrm{S}$ and (b) $135^{\circ} \mathrm{E}$ at $8^{\circ} \mathrm{N}$. Positive transport is northward. (c) Transport at $8^{\circ} \mathrm{S}$ (solid) and $8^{\circ} \mathrm{N}$ (dashed) integrated downward. All units are Sverdrups.

Hemisphere transport (Figs. 12a,c) is quantitatively and qualitatively similar to their results, but there is a significant disagreement north of the equator (Fig. $12 \mathrm{~b}$ ). While the overall shape of the transport is similar at $8^{\circ} \mathrm{N}$, the model has a net northward flow across this section below $41 \mathrm{~m}$. The discrepancies between OCCAM and JM99 are not likely due to their assump- tion of a 900-dbar level of no motion: we recalculated the OCCAM transports after subtracting the 900-dbar flow and the results were quite similar. These differences might be due to the fact that the Ekman transport in OCCAM is felt below the 41-m level or, conversely, that the mixed layer in JM99 is shallow: lighter water masses are included in their calculation but are excluded in ours. It is also possible that the OCCAM's western boundary current is too wide and our analysis is picking up some of the northward flow along the boundary, making our interior flow seem more northward than JM99.

JM99 and Fig. 12 include all water parcels crossing these latitudes and not just those that end up in the EUC. Our trajectory analysis, which only accounts for the flows into the EUC, shows a total interior flow of 3.6 Sv from the South Pacific (across $13^{\circ} \mathrm{S}$ east of $165^{\circ} \mathrm{E}$ ) and only $0.2 \mathrm{~Sv}$ from the North Pacific (across $10^{\circ} \mathrm{N}$ east of $135^{\circ} \mathrm{E}$ ). We should note that it is possible that there are interior paths from either hemisphere that join the EUC east of $140^{\circ} \mathrm{W}$ and are therefore not counted in our analysis. The strength of the EUC, however, gradually weakens toward the east, so additional interior contributions are likely to be small. Plots of the cumulative ventilation of the EUC against time and the total volume from each pentad (Fig. 6b) show, in agreement with the CFC estimates of Fine et al. (1994) and Fine et al. (2001), that the median age of all ventilated particles at the EUC at $140^{\circ} \mathrm{W}$ is $19 \mathrm{yr}$. About $70 \%$ had a transit time of less than $50 \mathrm{yr}$, and $85 \%$ have an age of less than $100 \mathrm{yr}$. Trajectories from the south take longer to arrive at the EUC than the trajectories from the north because of the fact that North Pacific water is unlikely to cross the equator, whereas $79 \%$ of the trajectories starting south of $13^{\circ} \mathrm{S}$ cross $5^{\circ} \mathrm{N}$.

The data for our analysis is from the seasonally averaged output of the OCCAM model and there are likely differences between our results and those that would be derived from a complete set of observations. The footprints (Fig. 7) and the transit times (Fig. 6 and Figs. 9b-d) are consistent with the observations derived from tracer studies. This study provides a more complete picture than is possible from observations, but it is limited by the quality of the model simulation. As models improve, the trajectory algorithm will become increasingly useful.

Acknowledgments. The authors thank the editors and reviewers for their most helpful comments and patience with this review process; the paper is surely better now for their assistance. Author MC was supported by NSF Grant ATM 03-50702 and NOAA Grant NA03OAR4320179. 


\section{REFERENCES}

Blanke, B., and S. Raynaud, 1997: Kinematics of the Pacific Equatorial Undercurrent: An Eulerian mean and residual mean approach from GCM results. J. Phys. Oceanogr., 27, 10381053.

Cromwell, T., R. B. Montgomery, and E. D. Stroup, 1954: Equatorial undercurrent in the Pacific Ocean revealed by new methods. Science, 119, 648-649.

de Vries, P., and K. Döös, 2001: Calculating residual mean trajectories using time-dependent velocity fields. J. Atmos. Oceanic Technol., 18, 1092-1101.

Döös, K., 1995: Interocean exchange of water masses. J. Geophys. Res., 100, 13 499-13 514.

Drijfhout, S. S., P. de Vries, K. Doos, and A. C. Coward, 2003: Impact of eddy-induced transport on the Lagrangian structure of the upper branch of the thermohaline circulation. $J$. Phys. Oceanogr., 33, 2141-2155.

Fine, R. A., R. Lukas, F. M. Bingham, M. J. Warner, and R. H. Gammon, 1994: The western equatorial Pacific: A water mass crossroads. J. Geophys. Res., 99, 25 063-25 080.

—, K. A. Maillet, K. F. Sullivan, and D. Willey, 2001: Circulation and ventilation flux of the Pacific Ocean. J. Geophys. Res., 106, 22 159-22 178.

Gibson, R., P. Kållberg, S. Uppala, A. Hernandez, A. Nomura, and E. Serrano, 1997: The ERA description. The ECMWF Re-Analysis Project Report Series 1, ECMWF, 77 pp.

Gu, D., and S. G. H. Philander, 1997: Interdecadal climate fluctuations that depend on exchange between the Tropics and extratropics. Science, 275, 805-807.

Hazeleger, W., P. de Vries, and G. J. Van Oldenborgh, 2001a: Do tropical cells ventilate the Indo-Pacific equatorial thermocline? Geophys. Res. Lett., 28, 1763-1766.

_-, M. Visbeck, M. Cane, A. Karspeck, and N. Naik, 2001b: Decadal upper ocean temperature variability in the tropical Pacific. J. Geophys. Res., 106, 8971-8988.

-, P. de Vries, and Y. Friocourt, 2003: Sources of the equatorial undercurrent in the Atlantic in a high-resolution ocean model. J. Phys. Oceanogr., 33, 677-693.

Huang, B., and Z. Liu, 1999: Pacific subtropical-tropical thermocline water exchange in the National Centers for Environmental Prediction ocean model. J. Geophys. Res., 104, $11065-11076$

Johnson, G. C., and M. J. McPhaden, 1999: Interior pycnocline flow from the subtropical to the equatorial Pacific Ocean. $J$. Phys. Oceanogr., 29, 3073-3089.

Killworth, P. D., 1996: Time interpolation of forcing fields in ocean models. J. Phys. Oceanogr., 26, 136-143.

Lee, M. M., A. C. Coward, and A. J. G. Nurser, 2002: Spurious diapycnal mixing of the deep waters in an eddy-permitting global ocean model. J. Phys. Oceanogr., 32, 1522-1535.

Levitus, S., and T. P. Boyer, 1994: Temperature. Vol. 4, World Ocean Atlas 1994, NOAA Atlas NESDIS 4, 117 pp.

- R. Burgett, and T. P. Boyer, 1994: Salinity. Vol. 4, World Ocean Atlas 1994, NOAA Atlas NESDIS 3, 99 pp.

Lu, P., J. P. McCreary, and B. A. Klinger, 1998: Meridional circulation cells and the source waters of the Pacific Equatorial Undercurrent. J. Phys. Oceanogr., 28, 62-84.

Lukas, R., and E. Firing, 1984: The geostrophic balance of the Pacific Equatorial Undercurrent. Deep-Sea Res., 31, 61-66.

McDougall, T. J., 1998: Three-dimensional residual mean theory. Ocean Modelling and Parameterization, E. P. Chassignet and J. Veron, Eds., Kluwer, 269-302.

McIntosh, P. C., and T. J. McDougall, 1996: Isopycnal averaging and residual mean circulation. J. Phys. Oceanogr., 26, 16551660.

Pacanowski, R. C., and S. G. H. Philander, 1981: Parameterization of vertical mixing in numerical models of tropical oceans. $J$. Phys. Oceanogr., 11, 1443-1451.

Rodgers, K., B. Blanke, G. Madec, O. Aumont, P. Caias, and J. C. Dutay, 2003: Extratropical sources of equatorial Pacific upwelling in an OGCM. Geophys. Res. Lett., 30, 1084, doi:10.1029/2002GL016003.

Saunders, P. M., A. C. Coward, and B. A. de Cuevas, 1999: Circulation of the Pacific Ocean seen in a global ocean model: Ocean Circulation and Climate Advanced Modelling project (OCCAM). J. Geophys. Res., 104, 18 281-18 299.

Schneider, N., S. Venzke, A. J. Miller, D. W. Pierce, T. Barnett, C. Deser, and M. Latif, 1999: Pacific thermocline bridge revisited. Geophys. Res. Lett., 26, 1329-1332.

Tsuchiya, M., 1981: The origin of the Pacific Equatorial $13^{\circ} \mathrm{C}$ Water. J. Phys. Oceanogr., 11, 794-812.

— , R. Lukas, R. A. Fine, E. Firing, and E. Lindstrom, 1989: Source waters of the Pacific Equatorial Undercurrent. Progress in Oceanography, Vol. 23, Pergamon, 101-147.

Webb, D. J., A. C. Coward, B. A. de Cuevas, and C. S. Gwilliam, 1997: A multiprocessor ocean general circulation model using message passing. J. Atmos. Oceanic Technol., 14, 175-183.

- B. A. de Cuevas, and A. C. Coward, 1998: The first main run of the OCCAM global ocean model. Southampton Oceanography Centre Internal Rep. 34, 44 pp. [Available from Southampton Oceanography Centre, Empress Dock, Southampton SO14 3ZH, United Kingdom.]

Wyrtki, K., and B. Kilonsky, 1984: Mean water and current structure during the Hawaii-to-Tahiti Shuttle Experiment. J. Phys. Oceanogr., 14, 242-254.

Zhang, R. H., L. M. Rothstein, and A. J. Busalacchi, 1998: Origin of upper-ocean warming and El Niño change on decadal time scales in the tropical Pacific Ocean. Nature, 391, 879-882. 